\title{
AGÊNCIA EPISTÊMICA, NATURALISMO E NORMATIVIDADE
}

\author{
Ana Margarete B. de Freitas ${ }^{1}$
}

\begin{abstract}
RESUMO
O objetivo deste trabalho é apresentar um modelo de agência epistêmica que atenda ao projeto normativo da epistemologia, ao mesmo tempo em que satisfaz as intuições naturalistas sobre o funcionamento cognitivo humano. A agência epistêmica é um dos tópicos centrais de discussões na epistemologia contemporânea, sendo um elemento essencial para a fundamentação da Epistemologia das Virtudes de Ernest Sosa, que compreende as performances cognitivas humanas como virtudes intelectuais. $\mathrm{O}$ desenvolvimento, nas últimas décadas, de pesquisas no ramo da Psicologia Cognitiva, tem apoiado as argumentações de filósofos naturalistas que contestam a imagem do agente epistêmico como defendida por Sosa e apontam para a impossibilidade de haver agência relacionada aos processos de formação de crenças. Levando em conta este contexto e com base nas concepções de Joëlle Proust sobre a estrutura das ações mentais, apresento um caso hipotético que tenta estabelecer as bases para uma concepção de Agência Epistêmica Híbrida. A adesão à esta perspectiva sobre a agência epistêmica leva a uma visão mais realista sobre o papel epistêmico dos agentes humanos e a uma compreensão da normatividade epistêmica voltada para fins epistêmico-motivacionais.
\end{abstract}

Palavras-chave: Agência Epistêmica. Naturalismo. Metacognição. Joëlle Proust. Ernest Sosa.

\begin{abstract}
The objective of this work is to present a model of epistemic agency that seeks to attend the normative project of epistemology, while satisfying the naturalistic intuitions about human cognitive functioning. Epistemic agency is one of the central topics of discussion in contemporary epistemology, being an essential element for the foundation of Ernest Sosa's Epistemology of Virtues, which understands human cognitive performances as intellectual virtues. The development, in recent decades, of research in the field of Cognitive Psychology, has supported the arguments of naturalist philosophers who challenge the image of the epistemic agent as defended by Sosa and point to the impossibility of having an agency related to the processes of belief formation. Taking this context into account and based on Joëlle Proust's conceptions about the structure of mental actions, I present a hypothetical case that tries to establish the bases for a concept of Hybrid Epistemic

\footnotetext{
${ }^{1}$ Psicóloga e Doutoranda em Filosofia pela UFBA.

E-mail: anamargarete11@yahoo.com.br.
} 
Agency. Adherence to this perspective on epistemic agency leads to a more realistic view of the epistemic role of human agents and to an understanding of epistemic normativity aimed at epistemic-motivational purposes.

Keywords: Epistemic Agency. Naturalism. Metacognition. Joëlle Proust. Ernest Sosa.

\section{Introdução}

A noção de agência, em filosofia da ação (VELLEMAN, 1992; DAVIDSON, 2001a, 2001b; ENGEL, 2010; SCHLOSSER, 2015), está diretamente relacionada à ideia de ação humana, isto é, à manifestação da capacidade de agir intencionalmente, optando por escolher de forma deliberada um curso de ação sobre outro. Em epistemologia, agência diz respeito à performance do sujeito cognitivo no processo de formação de suas crenças. Este contato cognitivo do sujeito com uma proposição verdadeira sobre o mundo tem sido um dos objetos de estudo da epistemologia desde os seus primórdios. A atividade de compreender a forma como produzimos conhecimento deu origem a uma série de concepções sobre como atuamos no domínio epistêmico, sendo a Epistemologia das Virtudes de Ernest Sosa (1980, 1991, 2007, 2009, 2011, 2015) uma das posições mais influentes na contemporaneidade.

Na Epistemologia das Virtudes de Sosa, a força das avaliações epistêmicas normativas é derivada das virtudes intelectuais do agente - faculdades cognitivas como percepção, memória, reflexão etc. Ernest Sosa compreende a noção de conhecimento como uma realização cognitiva do agente em dois níveis: a crença que é corretamente atribuída à competência do sujeito exercida nas suas condições apropriadas, como por exemplo, as crenças perceptuais, que são adquiridas passivamente - conhecimento animal (SOSA, 2007); e o estado epistêmico que, além de ser atribuído à competência do agente, possui a característica de ser defensável, no sentido de que o agente possui um amplo entendimento da sua crença, o endosso reflexivo da confiabilidade das fontes - conhecimento reflexivo (SOSA, 2007). Nesta perspectiva, é o agente epistêmico e não as suas crenças que estão no foco das avaliações epistêmicas, podendo este ser elogiado ou censurado de acordo com o resultado das suas performances cognitivas. O crédito atribuí- 
do ao agente pela sua performance reflexiva constitui a noção de Agência Epistêmica Reflexiva:

[AgE-R] Ação reflexiva, autoconsciente e diretamente controlada que habilita o agente a realizar julgamentos, decidir no que crer, reconhecer a confiabilidade do processo de formação de suas crenças e defender a sua perspectiva epistêmica.

Embora esta versão da Epistemologia das Virtudes ${ }^{2}$ goze de um certo status explicativo por ter apresentado bons argumentos para as resoluções de problemas clássicos da epistemologia e incentivado uma série de debates que permitiu o desenvolvimento desta área até os dias atuais - influenciando, inclusive, outras áreas do saber como ética, política e educação -, filósofos, principalmente da vertente naturalista ${ }^{3}$, têm apresentado argumentações que contestam a imagem do agente epistêmico como defendida por Sosa. Essas contestações repercutem nas argumentações voltadas para o caráter normativo das ações humanas no domínio epistêmico, questionando diretamente a noção de agência epistêmica e o papel da reflexão na satisfação dos objetivos epistêmicos.

A maioria desses argumentos é baseado em evidências científicas produzidas, principalmente, pela Psicologia Cognitiva. As pesquisas empíricas nesta área, nos últimos $40 \operatorname{anos}^{4}$, mostram que as pessoas, normalmente,

\footnotetext{
${ }^{2}$ Há diferentes versões da epistemologia das virtudes na literatura, as principais são: as teorias das virtudes confiabilistas (SOSA, 1991; GOLDMAN, 1991; GRECO, 1999), que tratam as virtudes intelectuais como faculdades cognitivas, tais como percepção, visão, memória, etc.; e as teorias das virtudes responsabilistas (CODE, 1987; MONTMARQUET, 1993; ZAGZEBSKI, 1996), que tratam as virtudes intelectuais como traços de caráter do sujeito, tais como coragem intelectual, mente aberta, honestidade, etc. Segundo Fairweather (2014), o que unifica o campo da epistemologia das virtudes é a maneira única em que essas teorias colocam em primeiro plano a normatividade do conhecimento e o agente no centro da análise.

${ }^{3} \mathrm{O}$ naturalismo é um paradigma filosófico que sustenta a crença de que os problemas filosóficos devem ser tratados segundo os moldes das Ciências Naturais. Como afirma Quine (1980, p. 133), "conhecimento, mente e significado são parte do mesmo mundo com que eles têm a ver e eles têm de ser estudados com o mesmo espírito empírico que anima a ciência natural". Esse compromisso cientificista afirma que a moderna ciência natural fornece uma descrição verdadeira da natureza, e mais ainda, a única descrição verdadeira, capaz de fornecer a resposta à questão sobre o que há em última instância. Em relação à epistemologia, o naturalismo compreende o conhecimento como um fato natural, assim, nas investigações filosóficas acerca do conhecimento, os dados das pesquisas empíricas - desde uma perspectiva psicológica ou social - devem ser considerados nas análises.

${ }^{4}$ Um dos primeiros experimentos foi realizado em 1977 por Richard Nisbett e Timothy Wilson que publicaram o artigo "Telling More than We Can Know: Verbal Reports on Mental Processes" (Dizendo mais do que podemos saber: relatos verbais sobre os processos mentais). Nele, apresentaram um conjunto de experimentos cujos resultados apontam para
} 
ignoram as verdadeiras causas dos seus julgamentos epistêmicos, visto que muitos deles são realizados por processos cognitivos inconscientes ou influenciados por estímulos externos que passam desapercebidos pelos sujeitos. Desse modo, a ideia de que os seres humanos são agentes livres, responsáveis e autoconscientes acerca de seus julgamentos epistêmicos e que a reflexão é uma habilidade acurada, deliberada e capaz de produzir crenças mais confiáveis, é colocada sob suspeita, gerando um certo ceticismo na comunidade filosófica acerca da noção de agência epistêmica.

Um dos principais críticos é o filósofo Hilary Kornblith (2004, 2008, 2009, 2010, 2012, 2016a, 2016b). A partir de argumentos baseados em uma abordagem naturalista de investigação, ele tem afirmado que a noção de reflexão e o conceito de agência epistêmica - associado a esta habilidade cognitiva - não podem ser bem integrados ao caráter epistêmico do agente. As suas principais críticas se concentram nas seguintes afirmações: i) a capacidade reflexiva é mais limitada do que as idealizações acerca dela; ii) a capacidade de endossar reflexivamente uma crença não é um ato altamente consciente e diretamente controlado pelo indivíduo, pois é processada por mecanismos cognitivos subpessoais ${ }^{5}$; e iii) não há razão para determinar qualquer status especial às crenças obtidas através do escrutínio reflexivo, visto que elas são formadas pelos mesmos processos de formação de crenças não reflexivas. Desse modo, segundo Kornblith (2012), o apelo à agência epistêmica parece ser nada mais do que um bocado de mitologia, já que uma visão desmistificada da aquisição de crenças não deixa nenhum espaço para sua operação.

Uma outra vertente de investigação que põe em xeque a ideia de agência epistêmica e os poderes da reflexão são os estudos filosóficos dirigidos para a área da metacognição - a capacidade de pensar sobre o próprio pensamento ou de monitorar e controlar a própria atividade cognitiva. Joëlle Proust $(2008,2010,2013)$ é uma das filósofas contemporâneas mais influentes nesta área com publicações que defendem uma abordagem exclusivista/externalista da metacognição. Segundo esta concepção, a metacognição é

uma sistemática incapacidade da parte dos sujeitos em identificar as influências de certos estímulos em suas ações e decisões.

${ }^{5}$ Subpessoal está relacionado aqui à natureza insconsciente e não volitiva dos mecanismos cognitivos que operam nos processos de formação de crenças dos indivíduos. 
considerada um tipo natural que possui um conjunto de características funcionais próprias - independentes daquelas associadas à autoatribuição de estados mentais -, além disso, afirma que durante a atividade metacognitiva, pensamentos racionais não estão disponíveis para instruir um pensador sobre o que ele pode acreditar e, assim, permitir que ele seja responsável pelo seu arbítrio mental.

Essas críticas sugerem que as crenças formadas através da habilidade reflexiva - conhecimento reflexivo - não dependem da deliberação consciente e racional dos agentes, ameaçando a noção de agência epistêmica e, consequentemente, a imagem da epistemologia como uma disciplina normativa, voltada para as análises das ações dos agentes epistêmicos na produção de conhecimento. O aprofundamento do estudo sobre a natureza e as limitações dos processos cognitivos humanos tem levantado dúvidas sobre as capacidades humanas de controlar os seus processos mentais, de decidir e ser responsável pelas crenças que formam. Entretanto, uma vez que a sensibilidade às normas epistêmicas não depende da capacidade do agente controlar seus resultados cognitivos, resta a pergunta: Qual é, afinal, o papel do agente cognitivo no domínio epistêmico?

Uma resposta negativa a esta pergunta parece ser, no mínimo, contra intuitiva. Na vida comum, costumamos responsabilizar as pessoas pelas crenças que elas formam, censurando-as ou elogiando-as pelas suas performances cognitivas, assim como, habitualmente, empreendemos esforços cognitivos em busca da verdade na resolução de nossos problemas cotidianos e também na tomada de decisões importantes. Sentimos que aquilo que realizamos no âmbito mental, as nossas ações mentais - como refletir, buscar na memória, conjecturar, julgar etc. - interfere no resultado sobre aquilo que acreditamos; mas como integrar essa sensação aos resultados empíricos das ciências cognitivas?

Com base nestes questionamentos, o objetivo deste trabalho é apresentar um modelo de agência epistêmica que atenda ao projeto normativo da epistemologia, ao mesmo tempo em que satisfaz as intuições naturalistas sobre o funcionamento cognitivo humano. Para isso, concentrar-me-ei nas argumentações de Joëlle Proust desenvolvidas nos seus trabalhos a respeito do tema da metacognição. 
Na primeira parte, apresento a Definição Exclusivista acerca da metacognição como defendida por Proust $(2010,2013)$ e discuto suas três principais afirmações: i) as ações mentais e ordinárias - isto é, aquelas que realizamos na vida cotidiana como lavar pratos, arrumar malas, dirigir etc. não têm a mesma estrutura normativa básica, portanto, a avaliação epistêmica não é um componente de uma ação cognitiva do mesmo modo que o controle da ação é um elemento da ação ordinária; ii) a metacognição entendida como autoavaliação das próprias propriedades mentais é um componente constitutivo de toda ação mental, mas está ausente nas ações ordinárias; e iii) a metacognição não é uma habilidade exclusiva dos seres humanos, de modo que saber conceitualmente que sabe não é uma condição necessária para que a competência metacognitiva se desenvolva.

Na segunda parte, discorro sobre a proposta teórica de Proust (2001, 2013) de que as ações mentais possuem uma estrutura de duas camadas que permite que sejam regidas por requisitos instrumentais - que se referem ao desejo do agente de resolver uma questão ou tomar uma decisão - e normativos ou epistêmicos - que dizem respeito à meta epistêmica inerente à resolução da tarefa. Essa visão considera que, apesar do ato mental estar subordinado a uma ação mais abrangente que possui uma dada utilidade, a avaliação metacognitiva, responsável por aplicar as normas epistêmicas relacionadas à ação, é inteiramente realizada num nível subpessoal - controlada pelo ambiente dinâmico de maneira opaca, sem a participação controlada e consciente do agente -, levando ao ceticismo sobre os poderes da agência epistêmica humana.

$\mathrm{Na}$ terceira parte, defendo que apesar de as crenças serem um estado mental produzido por mecanismos não volitivos, ainda assim é possível estabelecermos um papel para o agente cognitivo no domínio epistêmico, isto é, para a agência epistêmica; e apresento a definição de Agência Epistêmica Híbrida (AgE-H). Mediante um caso hipotético - o Caso da Terapeuta -, procuro demonstrar que o agir no mundo requer que os indivíduos realizem alterações das próprias propriedades mentais que, no contexto mais amplo das práticas sociais, podem interferir diretamente: i) no engajamento e na seleção das estratégias de aquisição de crenças; e ii) no emprego correto dos resultados epistêmicos na resolução de questões práticas. Isso exige um cer- 
to compromisso do indivíduo sobre sua ação no mundo, buscando não apenas alcançar a verdade, mas também a solução de problemas ordinários, demonstrando precisão, coerência e comprometimento com suas afirmações públicas.

Por fim, concluo propondo uma noção mais realista para os poderes da agência epistêmica e esclarecendo os limites de sua atuação dentro de uma visão naturalizada das ações mentais, assim como suas repercussões sobre a normatividade epistêmica.

\section{A definição exclusivista acerca da metacognição}

Ao longo do desenvolvimento das pesquisas acerca da metacognição, os teóricos têm se dividido em dois campos distintos sobre a forma de entender e estudar os processos metacognitivos, existindo uma dualidade teórica em relação a forma de interpretar o prefixo 'meta' que faz a conexão com a palavra 'cognição' (PROUST, 2010, 2013). De um lado, temos os teóricos que compreendem 'meta' em termos de pensar sobre o próprio pensamento, como uma questão de atribuir pensamentos a si mesmo e aos outros, isto é, "em termos de ter o conhecimento teórico que se conhece, compreende, lembra, percebe, e assim por diante, e do que ou quando se sabe disso" (PROUST, 2013, p. 3, grifos da autora) - Visão Atributiva. Do outro lado, há os que definem a palavra 'meta' "em termos da atividade de monitorar a cognição" (PROUST, 2013, p. 3, grifo meu) - Visão Avaliativa. Enquanto a visão atributiva está relacionada a uma interpretação internalista acerca dos processos metacognitivos, a visão avaliativa se baseia numa concepção externalista destes processos.

Proust (2013) acredita que considerações teóricas derivadas de estudos sobre o desenvolvimento humano, a aprendizagem humana e a evolução da espécie não deixam espaço para defender posições internalistas acerca da metacognição. Na sua visão, é potencialmente enganosa a suposição generalizada das posições internalistas de que

os mecanismos que servem a uma determinada função - digamos, decisão epistêmica - devem refletir diretamente nossa maneira de expressar essa função verbalmente, como o que é racional fazer ou pensar, dados os estados mentais antecedentes. Assim como o raci- 
ocínio lógico ou probabilístico acaba por se basear em heurísticas que têm pouco a ver com a ciência da lógica e da teoria da probabilidade, a metacognição pode confiar em heurísticas que não precisam envolver o conhecimento proposicional que se tem do conteúdo mental (PROUST, 2013, p. 1-2).

Os internistas metacognitivos compreendem que para monitorar ou endossar as próprias disposições mentais é necessário que os sujeitos formem crenças sobre suas atitudes proposicionais e seus conteúdos associados, de modo que o monitoramento dos estados mentais seja uma consequência causal do conhecimento dos próprios conteúdos mentais. Proust (2010, 2013), chama esta conceituação de Definição Inclusivista, pois implica a inclusão da capacidade de atribuir estados mentais a si mesmo ou a outros como condição para a possibilidade de realizar avaliações cognitivas. As habilidades metacognitivas, vistas desta forma, motivam o internalismo epistêmico, a visão de que o agente deve ser capaz de justificar as suas próprias crenças, apresentando razões para suas atitudes doxásticas com base nas suas habilidades epistêmicas e recursos cognitivos, como a introspecção $0^{6}$.

Proust (2013), notadamente, discorda da Definição Inclusivista acerca da metacognição, defendendo uma Definição Exclusivista que, baseada numa posição externalista, analisa a metacognição como um tipo natural, como um conjunto de processos cuja função é exclusivamente monitorar ou regular as ações cognitivas ou mentais, ou seja, como uma competência para a autoavaliação baseada, em parte, no conhecimento não analítico, com características processuais. A concepção Exclusivista da metacognição é apoiada em três reinvindicações principais: i) "as ações mentais e ordinárias não têm a mesma estrutura normativa básica" (p. 5); ii) "a metacognição, entendida como autoavaliação das próprias propriedades mentais previstas ou adquiridas, é um ingrediente constitutivo de toda ação mental, mas está

\footnotetext{
${ }^{6} \mathrm{Na}$ literatura, o internalismo é diferenciado em dois tipos: internalismo de acesso, segundo o qual para conferir justificação algo deve ser acessível ao sujeito de algum modo especial; e internalismo mentalista, perspectiva cujo o processo de conferir justificação está relacionado a algo que deve estar dentro do 'ponto de vista' do sujeito no mundo, algo que ele deve saber (ALSTON, 1986). O debate em torno do "internalismo epistêmico" possui diversos desdobramentos e não é objetivo deste trabalho aprofundá-lo. Para maiores detalhes sobre o internalismo epistêmico consultar Alston (1986, 1998), Chisholm (1988, 1989), Kornblith (2001), Bonjour e Sosa (2003).
} 
ausente nas ações básicas comuns" (p. 5); e iii) “essa habilidade não é exclusiva dos seres humanos" (p. 5). Vamos analisar cada uma dessas afirmações.

\subsection{Ações mentais e ordinárias divergem quanto a sua estrutura normativa básica}

Em relação à afirmação (i), Proust $(2010,2013)$ observa que há uma intuição amplamente compartilhada por filósofos em geral de que ações mentais e ordinárias - aquelas que, normalmente, envolvem ações corporais ou físicas - possuem a mesma estrutura normativa básica ${ }^{7}$.

Segundo Proust (2013), esta intuição é derivada da definição de ação mental como um querer ou um tentar através do qual uma operação é "[1] chamada por causa de sua relação instrumental para um objetivo, e [2] é assim disponibilizada para processos executivos" (p. 186). A ação mental possui um conteúdo intencional como consequência causal da crença e do desejo do agente, e os estados mentais obtidos por intermédio da ação pertencem ao próprio sujeito que forma a intenção, de modo que as ações mentais são qualificadas como autodirecionadas, autoconscientes e autocontroladas, exigindo que o sujeito tenha a consciência de que ele age sobre si mesmo e que ele opera controlando as ações mentais que produzem o resultado esperado. Além disso, considera-se que, assim como as ações ordinárias, o agente ao realizar uma ação mental deve ter razões instrumentais para executá-la, sendo capaz de responder racionalmente pela sua ação. Tudo isso sugere que há uma analogia entre ações mentais e ações ordinárias, de modo que para cada atitude psicológica "espontânea", corresponderia uma espécie “controlada" dessa mesma atitude. Entretanto, Proust (2001) alega:

Filósofos tradicionais exploraram a visão de que julgar poderia ser um ato da vontade, influenciado, em parte, por um ato anterior de atenção voluntária, selecionando aqueles aspectos do assunto a serem usados como premissas. Conceber, imaginar, querer, planejar,

\footnotetext{
${ }^{7}$ É o caso do projeto epistemológico de Sosa, uma vez que a sua Epistemologia da Performance $(2003,2007,2011,2015)$ compreende as avaliações epistêmicas como ações com objetivos, tais quais outras performances humanas ordinárias como cozinhar, tocar um instrumento etc., de modo que ambas - ações mentais e ordinárias - estão sujeitas às avaliações normativas.
} 
raciocinar, sonhar, assim como desejar, também foram considerados pertencentes à extensão dos atos mentais. Essa proliferação exige alguns esclarecimentos (p. 1).

Na visão de Proust (2013, p. 6, grifo meu), "há uma profunda desanalogia entre ação mental e ação ordinária". Esses dois tipos de ação são naturalmente distintos, havendo uma autonomia da ação mental em relação à ação ordinária que é dada pela diferença entre as normas epistêmicas e as normas instrumentais. Enquanto as ações ordinárias podem ser caracterizadas na estrutura geral de "[t]er a intenção (desejar, ter razões) de ver o objetivo G realizado! (= causa a tentativa de H para que G seja realizado)" (PROUST, 2013, p. 150), utilizando para isso relações meios-fins, isto é, normas instrumentais; as ações mentais operam de forma completamente distinta.

As normas que governam as ações ordinárias derivam sua autoridade de intenções e desejos intrinsecamente motivadores, se baseiam na utilidade dos resultados, nas relações de custo-benefício e na eficácia das relações entre os meios e fins disponíveis. Assim, um agente pode formar crenças falsas ou desejos ilusórios a fim de evitar uma situação dolorosa ou de conviver melhor com a realidade que ele se encontra. Para Proust (2013, p. 6), "essas várias infelicidades não prejudicam constitutivamente o fato de que ele realizou uma ação".

Já no caso das ações mentais, embora essas normas instrumentais também estejam presentes na seleção das metas, há também um outro conjunto de normas que entram em jogo no processo, as normas constitutivas, que caracterizam, de fato, as normas epistêmicas. As normas constitutivas visam a verdade, coerência, relevância, exaustividade, entre outras, e o agente deve ser sensível a elas para poder executar ações epistêmicas. Proust (2013) afirma que algumas ações mentais são sensíveis a múltiplas normas como verdade e coerência. Para ela, a multiplicidade de normas existentes em algumas ações mentais é uma consequência da racionalidade limitada: "dados seus recursos cognitivos limitados, os agentes precisam se concentrar nos objetivos epistêmicos específicos que possam oferecer o melhor retorno em correção epistêmica e utilidade prática" (PROUST, 2013, p. 184). Essa variedade de normas pode ser bem recebida por pluralistas epistêmicos 
- aqueles que negam que a verdade seja o único objetivo epistêmico a ser perseguido. ${ }^{8}$

Essas normas não dependem do objetivo arbitrário do sujeito, pois ao realizar uma ação de planejar, por exemplo, o sujeito inevitavelmente encontra restrições objetivas mínimas, como coerência e relevância, que são necessárias para que esse episódio seja classificado como planejamento. Como aponta Proust (2013, p. 152),

[s]e um pensador pretendia chegar a conclusões, elaborar planos e assim por diante, independentemente de normas como relevância, coerência ou exaustividade, sua atividade mental resultante não contaria como uma ação mental de raciocínio ou planejamento. Seria apenas uma tentativa ilusória de planejar ou raciocinar. Um agente mental não pode, portanto, tentar $\varnothing$, sem ser sensível de forma bem-sucedida às normas que constituem realizar $\varnothing$.

Algumas das características relevantes das normas constitutivas sugerem que o fato do agente ser sensível a elas para executar ações epistêmicas não implica que ele precise possuir conceitos normativos como verdade ou coerência, nem que elas precisem ser exercitadas conscientemente e intencionalmente pelo agente para serem reconhecidas como restrições sobre o que pode ser feito mentalmente, além disso, elas possuem um caráter essencialmente receptivo, de modo que seu conteúdo e função psicológica são de um tipo não controlável pelo indivíduo (PROST, 2013).

Assim, Proust (2013) conclui que, diferente das ações ordinárias, as ações mentais apresentam dois tipos de motivos: um motivo instrumental que é realizado conforme necessidades informacionais básicas, como por exemplo, lembrar o nome de uma pessoa, julgar entre argumentos distintos, planejar uma viagem etc., motivando o próprio ato mental através do seu objetivo final em um determinado contexto; e um motivo normativo que envolve a execução de uma norma epistêmica específica dado o tipo de ação mental realizada, oferecendo uma avaliação da viabilidade do ato e de se as restrições a uma determinada norma (acurácia, coerência, simplicidade, etc.) foram cumpridas.

\footnotetext{
${ }^{8} \mathrm{O}$ debate filosófico sobre o monismo e o pluralismo epistêmico é extenso e inconclusivo, não fazendo parte do objeto de estudo deste trabalho. Para maiores informações sobre este debate consultar DePaul (2001), Alston (2005) e Kvanvig (2005).
} 
O quadro abaixo representa a diferença entre ações ordinárias e ações mentais:

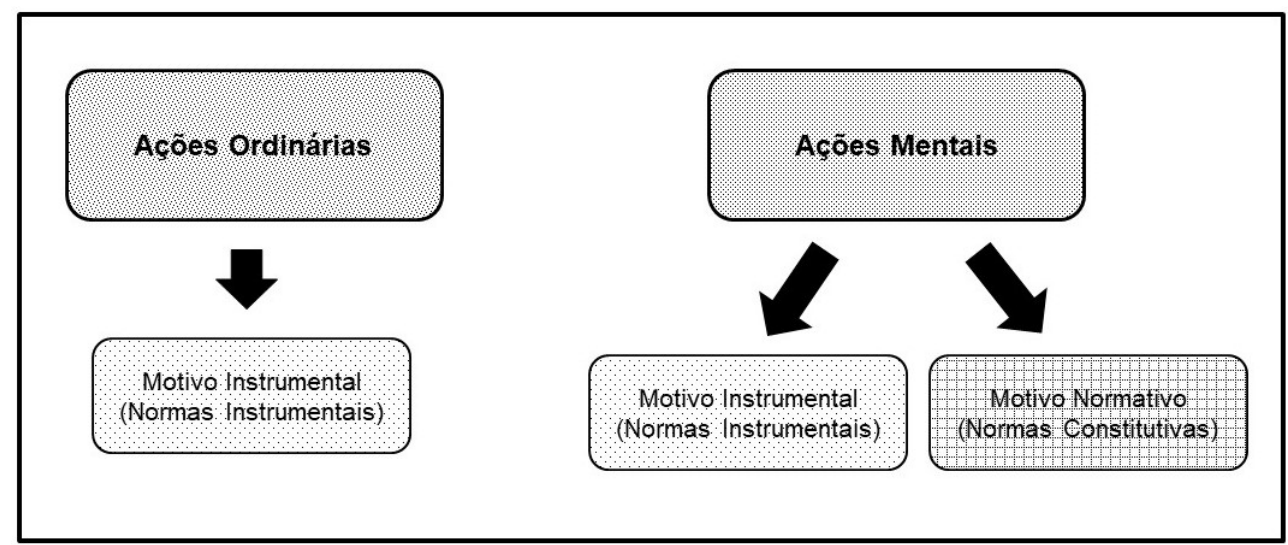

Quadro 1: diferença entre ações ordinárias e mentais.

\subsection{A metacognição faz parte de toda ação mental, mas está ausente nas ações básicas}

A afirmação (ii) - a metacognição, entendida como autoavaliação das próprias propriedades mentais previstas ou adquiridas, é um ingrediente constitutivo de toda ação mental, mas está ausente nas ações básicas comuns - é uma complementação do que foi esboçado sobre a afirmação (i). A metacognição como uma habilidade mental de monitorar o próprio pensamento, é regida pelas normas constitutivas envolvidas em todas as ações mentais, mas ausentes em ações ordinárias - como foi argumentado acima. Entretanto, filósofos, como Ernest Sosa $(2011,2016)$, insistem em tomar a metacognição como uma forma de monitoramento das ações ordinárias, considerando as normas usadas na agência mental como apenas um caso especial das mesmas normas utilizadas para avaliar a agência ordinária. Do ponto de vista desta interpretação, a autoavaliação é entendida "como um conjunto de perguntas dirigidas a si mesmo, que ajudam um agente a decidir se deve executar uma determinada ação mental ou se a ação realizada é válida" (PROUST, 2013, p. 7, grifo meu).

A noção de conhecimento reflexivo defendida por Sosa $(2009,2015)$ envolve a capacidade do agente de autoavaliação - análise do risco de falhar ou obter sucesso na execução - das próprias performances através de virtudes racionais de ordem superior, como autoconsciência e reflexão crítica, o que lhe permite ter uma perspectiva interna das suas próprias disposições 
cognitivas e da sua relação com o ambiente. Essa autoconsciência disposicional e ambiental, juntamente com o escrutínio reflexivo, vão determinar se suas crenças de primeira ordem estão bem justificadas ou não, ou seja, a correção da crença depende da manifestação das virtudes de ordem superior do agente. Neste caso, um agente virtuoso deve se perguntar: 'posso julgar corretamente que $p$ ?', 'a crença $y$ é mais racional que a crença $x$ ?, com o objetivo de formar ou revisar julgamentos à luz de suas respostas a essas perguntas autodirigidas.

Estes questionamentos se configuram da mesma forma que o monitoramento da ação ordinária, com um objetivo próprio, voltado para a autoavaliação, articulado em termos conceituais, o que Proust (2013, p. 8) chama de Metacognição Analítica - "compreensão explícita de atitudes, normas epistêmicas e de si mesmo como um agente epistêmico". É importante notar que Sosa defende uma posição que remete à visão atributiva da metacognição, uma vez que considera que a representação do conteúdo de primeira ordem não pode ser avaliada, a menos que seja metarepresentada, através da meta-aptidão (reflexão) - uma performance meta-apta em que o agente reflete sobre suas crenças de primeira ordem, formando crenças de segunda ordem.

Entretanto, Proust (2008, 2010, 2013) considera essa interpretação acerca da metacognição equivocada. Como vimos acima, ela defende uma visão avaliativa da metacognição, isto é, que compreende a metacognição como uma função exclusiva de autoavaliação processual, que pode ou não ser enriquecida pela capacidade de atribuir estados mentais a si mesmo?. Nesta perspectiva, a metacognição, como um componente presente em todas as ações mentais, se divide em dois tipos de avaliação: a) a Autoavaliação (Self-probing) e b) a Pós-avaliação (Post-evaluation).

A autoavaliação trabalha de forma preditiva, ela tem a função de avaliar se um pensador é capaz de executar uma dada ação mental, dentro de um determinado contexto e dado os recursos mentais disponíveis naquele

\footnotetext{
${ }^{9}$ De acordo Proust (2013), a metacognição é considerada um sistema mais básico com uma estrutura representacional não proposicional. Entretanto, em humanos, que possuem capacidade de representação proposicional, a informação que foi formada num formato mais básico pode ser redescrita e, portanto, enriquecida, usando uma representação mais sofisticada, podendo ser conceituada, com possibilidades descritivas e inferenciais.
} 
momento, isto é, realiza uma análise das pré-condições mentais do agente a fim de prever a viabilidade de uma ação mental (Ex: 'sou capaz de lembrar esta palavra?'). Já a pós-avaliação atua de forma retrospectiva, sua função é estabelecer de uma maneira prática se a ação mental realizada pelo agente foi completada com sucesso ou não (Ex: 'essa palavra é a que eu estava procurando?').

Embora estes dois tipos de avaliação tenham funções distintas, Proust (2013) afirma que eles apresentam semelhanças em vários aspectos: i) "ambos avaliam o sucesso de maneira modular, estritamente fechada [strictly closed-loop]" (p. 189, grifo da autora), isto é, eles funcionam em um nível subpessoal, onde não é necessário utilizar uma estrutura conceitual rica para fazer inferências e generalizações a partir dessa avaliação; ii) "ambos têm uma forma de avaliar intensiva, sensível ao gradiente, ao invés de julgar discretamente se a ação mental é possível ou não, bem sucedida ou não" (p. 190, grifos da autora), ou seja, as avalições se baseiam em sentimentos epistêmicos - sinais afetivos ou emocionais - que podem resultar de comparadores que parecem não utilizar uma metarrepresentação dos fatos, constituindo em conteúdos não conceituais que permite ao pensador representar o mundo independentemente dele possuir ou não conceitos necessário para especificar seu conteúdo; iii) “em ambos os casos, os sentimentos motivam os pensadores a agir mentalmente" (p. 190), assim, na autoinvestigação um sentimento leva um sujeito a imediatamente executar a ação mental ou abster-se de realizá-la - neste caso, ele irá selecionar outra forma de responder à situação -, e na pós-avaliação o sentimento leva o sujeito a aceitar a ação realizada como bem sucedida ou não - neste último caso, ele irá considerar ações corretivas; e, por último iv) "a autoinvestigação e pós-avaliação estão internamente relacionadas entre si e são partes do processo causal estendido, por meio do qual a tentativa mental é executada" (p. 190), isso significa que estes dois tipos de avaliação atuam de maneira integrada, de modo que a pergunta que a autoavaliação indaga - ‘eu sei o nome dela?' - é imitada pela questão que a pós-avaliação levanta - 'seu nome, certamente, é Suzana'.

Desse modo, os episódios metacognitivos ajudam os agentes a realizar as suas ações mentais, constituindo-se como uma parte desta ação que 
visa produzir um resultado cognitivo específico: executar a avaliação preditiva e retrospectiva das ações mentais com base em normas epistêmicas (verdade, coerência, inteligibilidade, relevância etc.). Quando um sujeito, por exemplo, se engaja em uma ação mental de considerar visões alternativas sobre um mesmo tema, há um componente motivacional instrumental que é dado pela utilidade da ação, mas há também um outro componente normativo que envolve a execução das normas epistêmicas que opera através da metacognição. Nas palavras de Proust (2013, p. 192) “o escopo de uma única ação mental sobrevém em uma continuidade funcional, normativa e motivacional entre as fases metacognitivas e o núcleo da ação mental". Isso significa que os episódios metacognitivos de autoavaliação e pós-avaliação não se configuram como ações mentais independentes ${ }^{10}$ da ação mental principal - como o exemplo dado acima de considerar visões alternativas sobre um mesmo tema -, mas sim como uma parte constitutiva da ação mental que eles estão associados, ou seja, passos necessários à realização de toda ação mental ${ }^{11}$.

Para Proust (2013, p. 190-191),

[e]ssas várias características sugerem fortemente que a metacognição forma um tipo natural dentro das habilidades mentais; sua função geral é avaliar a adequação cognitiva das disposições de uma pessoa para agir mentalmente. As diferenças na orientação temporal das duas espécies de intervenções metacognitivas não são características acidentais, mas sim uma consequência das condições racionais da própria agência, o que implica previsão de habilidade e avaliação de resultados.

\footnotetext{
${ }^{10}$ Para Proust $(2008,2013)$, é possível que agentes humanos desejem se envolver em investigações hiperreflexivas, para saber se eles podem realizar uma tarefa cognitiva de primeira ordem independente de qualquer outro objetivo. Embora esses casos de autoinvestigação mental sejam considerados atípicos do ponto de vista da avaliação metacognitiva, é possível que a metacognição processual, quando ligada a uma compreensão analítica do conhecimento, permita que a autoinvestigação seja perseguida como uma ação mental independente.

${ }^{11}$ Proust (2001) faz uma distinção entre ações mentais e operações mentais. Essa distinção é importante, pois sinaliza que a metacognição só está presente em casos de ações mentais, já que em casos de operações mentais a avaliação de recursos não é necessária e, na maioria dos casos deste tipo o sujeito responde de forma imediata, isto é, sem atraso, sem sinal de erro, não precisando envolver nenhuma forma de sentimento noético ou epistêmico.
} 
O quadro abaixo representa a estrutura de uma ação mental:

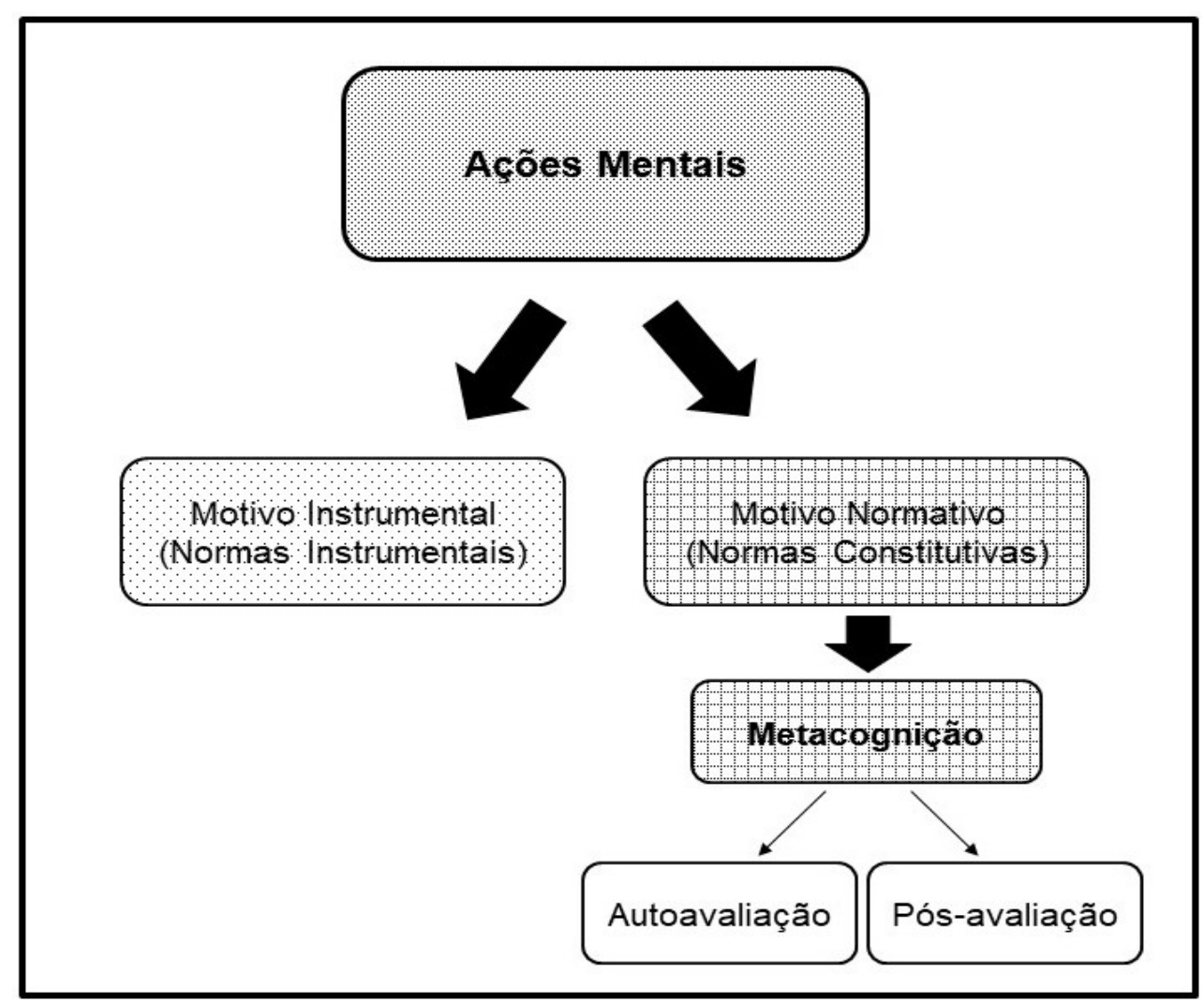

Quadro 2: estrutura de uma ação mental

\subsection{A metacognição não é uma habilidade exclusiva dos seres humanos}

Tendo em vista que a metacognição é parte de toda ação mental, é possível chegarmos à afirmação (iii) - que esta habilidade não é exclusiva dos seres humanos. De acordo com Proust (2013), muitos animais não humanos são capazes de agir mentalmente, eles são eficientes em lembrar e avaliar a sua confiabilidade na realização das suas tarefas. Isso leva a crer que a capacidade de representar conceitualmente as próprias atitudes de primeira ordem não pode ser uma condição necessária para que a competência metacognitiva se desenvolva.

Contrariando a afirmação de Sosa (2009) de que apenas humanos são capazes de metaaptidão - isto é, de analisar sua competência de primeira ordem e seu ambiente, avaliando o risco de falha ou sucesso na sua execução, através das suas habilidades reflexivas - Proust $(2008,2013)$ sustenta que as intervenções metacognitivas não implicam "saber reflexivamente". 
Quando um sujeito se engaja numa ação mental, a metacognição atua por meio da autoavaliação - que avalia a probabilidade em que ele será capaz de realizar a ação mental com sucesso (lembrar $r$, aprender $p$, conta $q$ etc.) -, e da pós-avaliação - que avalia a exatidão da recuperação informacional -, e isso não acarreta que o sujeito saiba reflexivamente que está realizando estas operações. A razão para esta afirmação é que crianças e animais não humanos, que não possuem a capacidade de atribuir estados mentais a si mesmos, foram encontrados realizando corretamente tarefas metacognitivas.

Evidências extraídas da Psicologia Comparada (SMITH et al, 2003; SMITH, 2005) sugerem que animais não humanos, como macacos e golfinhos, são capazes de avaliar adequadamente seu nível de autoconfiança em tarefas relativas à percepção e memória, nas quais eles podem responder sim, não ou incerto. Os resultados demonstram que eles parecem tomar decisões racionais com base nessas avaliações, pois foi observado que quando o estímulo alvo é difícil de discriminar perceptualmente ou de lembrar, os animais escolhem não oferecer uma resposta, se tal escolha for oferecida a eles, e sua confiabilidade aumenta à medida em que estão livres para responder ou não. Isso significa que alguns animais não humanos são capazes de reconhecer normas epistêmicas, mesmo na ausência de conceitos mentais e consciência reflexiva, ou seja, a metacognição processual ocorre em um nível subpessoal sem necessidade de metarepresentação.

Segundo Proust (2013), a resposta mais plausível para a sensibilidade às normas epistêmicas apresentadas tanto por crianças e animais não humanos quanto por humanos adultos pode ser encontrada nos estados afetivos: "Um sentimento 'diz' a um sujeito, de uma maneira prática, desarticulada e incorporada, como um determinado ato mental está se desenvolvendo em relação à sua norma constitutiva, sem precisar estar reflexivamente disponível para o crente" (p. 158). Esta afirmação contraria a alegação de Sosa $(2009,2015)$ de que a sensibilidade às normas epistêmicas depende, prioritariamente, da capacidade do agente conscientemente controlar os seus resultados cognitivos, o que o faz distinguir o conhecimento animal do conhecimento reflexivo, este último distintamente humano.

Na visão de Proust (2013), a sensibilidade às normas epistêmicas é rastreada por sentimentos epistêmicos, isto é, sentimentos noéticos consci- 
entes que são gerados por heurísticas inferenciais que operam de forma implícita e não intencional. São exemplos de sentimentos epistêmicos os sentimentos de conhecimento, a sensação de fluência, os fenômenos de "ponta da língua", os sentimentos de incerteza, o insight, o sentimento de estar perdido, entre outros.

Os sentimentos epistêmicos constituem o "formato representacional subjacente à metacognição processual" (PROUST, 2013, p. 158) e são apontados como uma fonte autorizável de informação não conceitual ${ }^{12}$ para adquirir crenças verdadeiras; eles "podem resultar de comparadores que parecem não pertencer a maneiras proposicionais de representar fatos" (PROUST, 2013, p. 111). Quando um sujeito realiza uma ação mental lembrar que $p$, por exemplo -, a autoavaliação é possibilitada pelos sentimentos da pessoa em relação a esta tarefa, são esses sentimentos subjetivos que rastreiam com segurança a adequação cognitiva da ação mental subsequente - um sentimento de que é possível realizar a ação; da mesma forma, na pós-avaliação são os sentimentos epistêmicos que rastreiam com segurança a verdade objetiva ou a correção da ação mental - um sentimento sobre a certeza que $p$. Desse modo, os sentimentos carregam informações epistêmicas subpessoais, eles atuam na metacognição processual auxiliando no controle e no monitoramento da incerteza subjetiva e o sujeito não tem acesso consciente sobre como chegou a esses resultados, ele apenas sente que é assim e age com base nesta informação ${ }^{13}$. Conforme Proust (2013, p. 146), os sentimentos noéticos

[...] carregam informações viáveis sobre a sensibilidade normativa das pessoas ao sucesso cognitivo do desempenho atual. Essa associação entre fato e norma é uma propriedade de todo comportamento normativo. Um fato descritivo foi selecionado (por evolução, por aprendizado?) como sendo relevante para a sensibilidade às normas, porque, primeiro, ele realmente prediz sucesso epistê-

\footnotetext{
${ }^{12}$ Nem todos os filósofos aceitam a existência de conteúdos não conceituais. Há um grande debate com visões diferentes sobre o papel dos conceitos no conteúdo, para maior aprofundamento sobre este tema ver Cussins (1990), McDowell (1994), Peacocke (2001), Bermúdez (2003).

13 Em humanos adultos, “os sentimentos epistêmicos oferecem uma transição racional para aquisição de conceitos relacionados ao conhecimento e de modais epistêmicos, ou seja, modos de conhecimento, como dúvidas, certezas, suposições, etc.” (PROUST, 2013, p. 140). De acordo com Burton (2017), em algumas situações, a sensação de saber advinda de sentimentos epistêmicos é sentida como um pensamento gerado a partir de elementos numa linha correta de raciocínio.
} 
mico; e, segundo, porque fornece acesso a pistas que os agentes podem usar para controlar normativamente suas ações. Essa visão é, portanto, uma visão expressivista sobre normas epistêmicas: os agentes inicialmente usam seus sentimentos (e seu rico conteúdo não conceitual) para avaliar seu desempenho de maneira sensível às normas. Além disso, a fluência sentida motiva os agentes a agir de maneira orientada por normas. O trabalho normativo, no entanto, ocorre "nos bastidores", por meio de mecanismos de recalibração que permitem que um sistema realinhe sua própria sensibilidade nas tentativas objetivas de performances anteriores.

Entretanto, Proust (2013) ressalta que estes sentimentos epistêmicos não são estritamente subjetivos, pelo contrário, eles são calibrados por restrições externas sociais e físicas, isto é, pela história dos resultados anteriores do indivíduo em relação às suas ações mentais. Isso significa que "a existência e a confiabilidade dos sentimentos epistêmicos sobrevêm, em parte, da existência e da qualidade do feedback fornecido" (p. 200, grifos da autora). De modo que sentimentos epistêmicos não são, necessariamente, precisos, eles podem ser ilusórios, levando o indivíduo a tomar decisões irracionais sobre como agir mentalmente, se for exposto a feedbacks inadequados.

Assim, diferente da posição defendida por Sosa (2009, 2011, 2015) - de que a meta-aptidão, isto é, a autoavaliação reflexiva sobre as crenças de primeira ordem, é uma virtude distintamente humana alcançada de forma autoconsciente e deliberada -, Proust $(2008,2013)$ sustenta uma perspectiva que compreende a metacognição como uma habilidade processual encontrada tanto em humanos quanto em animais não humanos. Esta habilidade ocorre sem a necessidade de conteúdo conceitual, sendo realizada em um nível subpessoal, de modo que não depende das capacidades introspectivas dos indivíduos, como controle direto e acesso consciente. A sensibilidade às normas epistêmicas (verdade, inteligibilidade, coerência etc.) resulta de sentimentos epistêmicos que operam a partir de uma arquitetura cognitiva que é moldada pelo ambiente dinâmico em que o indivíduo se encontra de forma opaca, isto é, sem que ele tenha consciência e controle dos fatos que o influenciam, restando-lhe apenas confiar nestes sentimentos para avaliar a viabilidade das suas ações mentais.

\section{Compreendendo a estrutura de duas camadas das ações mentais}


Como vimos na seção anterior, Proust (2013) defende que ações mentais e ações ordinárias possuem estruturas de funcionamento distintas, sendo as ações mentais regidas por dois tipos de normas: instrumentais e constitutivas (epistêmicas/normativas). Enquanto as ações ordinárias são regidas apenas por normas instrumentais, as ações mentais, além de possuírem um requisito instrumental, apresentam também um requisito normativo/epistêmico, regulado por normas epistêmicas constitutivas que impedem que seu conteúdo seja pré-especificado de acordo com a vontade do agente. Isso porque as ações mentais "herdam os requisitos normativos que já se aplicam às suas pré-condições e resultados epistêmicos" (PROUST, 2013, p. 152) Por exemplo, não é possível deliberar, para chegar a conclusões, independente de normas como coerência, relevância e precisão. Se isso chega a ocorrer, a atividade mental do sujeito não pode contar como uma ação mental de raciocínio, seria apenas uma tentativa ilusória de empreender uma deliberação. Assim, a diferença entre um raciocínio ruim e uma tentativa ilusória de raciocínio é que, no primeiro, o sujeito é sensível aos requisitos normativos associados, mas falha em cumpri-los, enquanto, no segundo, o sujeito deixa de ser sensível a eles.

Para que um agente possa executar ações epistêmicas é necessário que ele seja sensível às normas constitutivas. De acordo com Proust (2013, p. 152), “[...] isso não significa que o agente deva possuir conceitos normativos como verdade e coerência, mas sim que seja capaz de ajustar praticamente o seu desempenho mental em função de considerações de verdade, exaustividade ou relevância etc.”. Se engajar neste ajuste não implica que o agente esteja no controle do processo, nem que o resultado dependa das ações que ele empreenda, porém, para que o processo cognitivo ocorra, é necessário que o agente realmente se esforce na realização da tarefa cognitiva. Todo este encadeamento é o que Proust (2013) chama de estrutura de duas camadas das ações mentais.

$\mathrm{O}$ agir mentalmente possui uma estrutura de duas camadas justamente porque é regido por dois tipos de motivos - instrumental e normativo/ epistêmico - que conjuntamente regulam os atos mentais, possuindo um aspecto epistêmico-motivacional. O motivo instrumental diz respeito a alguma necessidade de informação básica que motiva o ato mental através do seu 
objetivo final e envolve aspectos implicados no contexto da ação que se referem a relações de custo-benefício, orientação correta da atenção e disposições presentes na seleção de estratégias para a realização do objetivo mental ${ }^{14}$. Por exemplo, diante da situação de ter esquecido a lista de compras, um sujeito pode selecionar estratégias de exaustão ou precisão para lembrar o conteúdo da lista, isso vai depender das disposições cognitivas do agente e das necessidades inerentes ao contexto no qual se encontra. Segundo Proust (2013, p. 155), “[s]elecionar um ato pode ser mais ou menos racional, dado um objetivo distal e um contexto". O contexto no qual o agente se encontra estimula diferentes objetivos mentais, por exemplo: se num contexto de conversa informal ou de discussão acadêmica ou de testemunho ocular etc., o agente pode estar certo ou errado ao acreditar que ele precisa oferecer uma resposta exaustiva ou refinada a uma pergunta.

Assim, a seleção de uma meta epistêmica específica responde às características de utilidade da ação mental, entretanto, o conteúdo epistêmico formado é normativamente autônomo e indiferente à utilidade, isto é, indiferente à razão do agente para ter adotado determinada estratégia. Isso porque a ação mental também possui um motivo normativo ou epistêmico, cuja função é aplicar os requisitos normativos constitutivos (verdade, coerência, exaustividade, relevância etc.) associados à estratégia escolhida pelo agente, por meio do monitoramento avaliativo da ação, isto é, uma avaliação da viabilidade do ato. Caso "a previsão não atinja um limiar de adequação, o motivo instrumental precisa ser revisado" (PROUST, 2013, p. 161). O agente mental é sensível a essas normas constitutivas, que selecionam e monitoram o desempenho mental, entretanto, essa sensibilidade é uma capacidade receptiva, ou seja, involuntária, de modo que "um conflito entre os fins epistêmicos a serem perseguidos em uma tarefa mental não afeta os requisitos normativos aplicáveis ao ato mental resultante" (PROUST, 2013, p. 154).

Com já exposto na seção acima, a sensibilidade às normas constitutivas é dada por meio de "sentimentos de viabilidade cognitiva [que] são formados passivamente na mente do agente como resultado de sua atenção ser

\footnotetext{
${ }^{14}$ Para Proust (2013), ações mentais podem ser executadas por uma norma específica sem que esta seja representada explicitamente para o agente, pois os agentes são treinados, por feedback prévio, aprendendo implicitamente que uma determinada norma governa a ação mental realizada em uma determinada tarefa ou contexto.
} 
canalizada em uma determinada direção epistêmica” (PROUST, 2013, p. 161-162). Esses sentimentos epistêmicos ou noéticos são características não conceituais que representam para o sujeito o que é epistemicamente certo decidir, quando este é confrontado com uma tarefa cognitiva. Eles são calibrados de acordo com a história dos resultados anteriores das ações mentais do sujeito ao longo do tempo e a sua confiabilidade depende da existência e da qualidade do feedback fornecido.

Proust (2013) apresenta um experimento mental, baseado no "cérebro na cuba", em que um cientista maluco fornece a Hillary - o sujeito do experimento - um feedback falso e regular sobre como ela se desempenha em um tipo de tarefa mental. Assim, sempre que ela realiza um tipo de ação mental, ela recebe um feedback tendencioso, sendo levada a acreditar que suas ações mentais deste tipo estão sempre corretas. Ela não tem como saber que está recebendo feedbacks equivocados e depois de um longo período de treino tendencioso, os sentimentos de Hillary se tornam altamente confiáveis. Isso provoca em Hillary o sentimento de que ela é capaz de realizar a ação, assim como ela tende a sentir que o resultado da ação está correto, mesmo que não esteja. Este experimento serve para mostrar que os sentimentos epistêmicos não são suficientes para guiar a ação mental e promover o comportamento racional, pois eles dependem do contexto em que o indivíduo está inserido e da sua capacidade em fornecer feedbacks dinâmicos precisos, conferindo-lhes uma dimensão externalista.

Tais sentimentos também mantêm uma relação causal com as propriedades dinâmicas dos estados cerebrais e são gerados em resposta às atividades dos seus marcadores somáticos ${ }^{15}$, podendo ser sentidos como mais ou menos fracos, transmitindo uma sensação de resultado mais ou menos iminente, e dotando o indivíduo de força motivacional ou confiança subjetiva para persistir - selecionando outra maneira de responder à situação atual ou abandonar uma tarefa mental.

\footnotetext{
${ }^{15}$ Um marcado somático é definido por Damásio, Everitt e Bishop (1996) como um sinal corporal cuja função é influenciar os processos de resposta a estímulos, em vários níveis de operação, alguns dos quais ocorrem abertamente ou conscientemente e outros ocultos ou inconscientemente. Esses sinais marcadores surgem em processos biorregulatórios, incluindo aqueles que se expressam em emoções e sentimentos, e agem de forma a influenciar o raciocínio humano e a tomada de decisões.
} 
Embora tenham características não conceituais, os sentimentos noéticos podem ser enriquecidos pelos seres humanos, por meio de uma atividade autointerpretativa com conceitos relacionados ao conhecimento e a incerteza epistêmica, usando palavras como adivinhar, conhecer, duvidar, entre outras, acrescentando seu potencial inferencial à orientação não conceitual (PROUST, 2013).

Os sentimentos epistêmicos são capazes de prever a probabilidade de uma disposição cumprir uma norma epistêmica - autoavaliação da ação e de avaliar os resultados da ação de forma retrospectiva - pós-avaliação da ação -, para informar se esta foi completada com sucesso ou não ${ }^{16}$. Assim, por exemplo, ao tentar lembrar a lista de compras, um agente, com o objetivo de ser exaustivo, realiza, de forma subpessoal, uma autoavaliação sobre a sua disposição de lembrar e, logo após, realiza outra avaliação referente ao resultado alcançado. Neste caso, segundo Proust (2013, p. 155, grifos da autora), há duas maneiras diferentes pelas quais um agente pode falhar em uma ação mental:

Ele pode selecionar um objetivo que não tem um bom motivo para selecionar (sendo exaustivo quando deveria ter como objetivo a precisão) [Erro instrumental]. Ou pode deixar de cumprir os requisitos normativos inerentes à estratégia que ele selecionou (selecionando o objetivo de ser exaustivo e deixando de fora a metade dos itens no conjunto da meta) [Erro epistêmico].

Ao selecionar uma estratégia, por exemplo, lembrar com exaustividade como no exemplo acima -, o agente leva em consideração o contexto e as relações de custo-benefício, assim como suas disposições. Assim que ele escolhe a estratégia, os requisitos normativos inerentes à estratégia escolhida são aplicados (exaustividade, relevância, coerência etc.), definindo as condições de satisfação da ação mental associada. Neste ponto, avaliações metacognitivas são realizadas: i) uma avaliação preditiva verificará a probabilidade de sucesso da ação mental escolhida naquele contexto, isto é, se as disposições cognitivas atuais do sujeito estão em conformidade com o requisito normativo - se o sujeito será capaz de lembrar com exaustividade um conjunto de itens; e ii) uma avaliação retrospectiva, que verificará se a ação mental foi correta e exaustiva - se o sujeito recuperou os nomes da lista. Desse modo, para cada requisito normativo empregado nas ações mentais, haverá diferentes formas de avaliações metacognitivas.

No caso da exaustividade, o agente tentará encontrar todos os verdadeiros positivos, aceitando o risco de produzir falsos positivos, mas sob a condição

\footnotetext{
${ }^{16}$ Em seres humanos que dominam conteúdos conceituais, além dos sentimentos epistêmicos, outros fatores como as crenças situacionais sobre sua competência em relação à tarefa envolvida, podem orientá-los nos processos autoavaliativos (PROUST, 2013).
} 
de incluir todas as respostas verdadeiras ao seu resultado. O sujeito é sensível aos requisitos normativos associados à estratégia, mas pode falhar em cumpri-los, e isso é algo que não está sob seu controle voluntário. Ele pode falhar na avaliação preditiva, prevendo erroneamente sua probabilidade de sucesso ao ser exaustivo e pode também deixar de fora uma boa parte dos itens, pois pode apresentar de forma indevida uma imaginação ao invés de uma lembrança, seguindo, de forma não intencional, uma norma de fluên$\mathrm{cia}^{17}$ ao invés de uma norma de exaustividade.

Assim, quando o indivíduo orienta a sua atenção com base em uma razão instrumental lembrar os itens da lista de compras - ele cria uma pressão única sobre a autoavaliação, ins talando uma condição pré e pós-avaliativa para a ação mental. Proust (2013, p 162) captura esta estrutura complexa de uma ação mental por meio da seguinte definição:

(C3) Estar motivado para realizar o objetivo G (= causas) tentando obter $\mathrm{H}$ a fim de ver $\mathrm{G}$ realizado, se aproveitando das disposições cognitivas e da sensibilidade às normas para $\mathrm{H}$ produzir $\mathrm{G}$ de maneira confiável. Essa caracterização enfatiza a associação funcional de normatividade e receptividade.

Então, a necessidade de uma informação básica motiva um ato mental, e o conteúdo epistêmico, fruto desta ação, é normativamente autônomo, uma vez que segue os requisitos normativos constitutivos associados a ela, por meio de avaliações processuais metacognitivas.

A partir dessa análise, podemos concluir que o agente exerce um controle no processo de aquisição de crenças apenas na medida em que ele é capaz de controlar e regular os seus processos de concentração e atenção ${ }^{18}$, mantendo um ajuste consciente na realização da tarefa mental e exercendo algum esforço cognitivo na direção instrumental do seu objetivo. Já o conteúdo epistêmico, resultante dos processos metacognitivos, não está sob o seu controle, pois é regulado por sentimentos epistêmicos, que dependem do ambiente dinâmico - social e físico - no qual o sujeito está inserido para calibrá-los adequadamente. $\mathrm{O}$ sujeito não tem uma maneira introspectiva de saber que seus sentimentos estão calibrados corretamente ou não - ele depende dos outros e do mundo para lhe dar esse feedback. Desse modo, o agente mental não tem nenhum controle sobre o resultado da sua ação mental, restando-lhe apenas confiar nos seus sentimentos epistêmicos. De acor-

\footnotetext{
${ }^{17}$ Uma norma de fluência é "uma norma epistêmica cuja função é aproximar uma norma da verdade" (PROUST, 2013, p. 125). Esta norma dá preferência às ações cognitivas que podem ser realizadas com menor esforço. Segundo Schwarz e Clore (1996), sujeitos humanos, de forma não deliberada, tendem a selecionar a fluência para avaliar tarefas sem muita importância.

18 Exemplos de tarefas que exigem concentração e atenção são: sondar a memória para identificar algum registro específico, verificar a validade lógica de um argumento, comparar visões alternativas, selecionar fontes de informação confiáveis, etc.
} 
do com Proust (2013, p. 206), mesmo um agente equipado com habilidades de leitura da mente, e capaz de compreender as limitações de sua aptidão para governar a si mesmo, ainda teria, em última análise, que depender de seus sentimentos para avaliar a viabilidade de suas ações mentais.

Assim, a estrutura da ação mental em duas camadas sugere que as ações mentais são tipos naturais cuja estrutura reflete um caráter híbrido, pois envolve um aspecto prático/instrumental e um aspecto epistêmico/normativo. Estes dois componentes são claramente distintos e relacionados: i) enquanto o primeiro se refere ao engajamento do agente na ação, considerando as necessidades de um determinado contexto na escolha das estratégias adequadas à meta; ii) o segundo não depende do objetivo arbitrário do agente, pois envolve processos metacognitivos realizados num nível subpessoal que aplicam as normas epistêmicas constitutivas da estratégia selecionada. Estas avaliações metacognitivas não podem ser caracterizadas como ações mentais independentes, pois elas incorporam apenas um dos passos necessários para a realização de toda ação mental.

\subsection{Eliciando uma ação mental}

Quando nos observarmos na vida cotidiana, é possível perceber que não realizamos ações mentais a todo momento, a maioria das nossas atitudes mentais parece automática e sem esforço. Podemos perceber pessoas e objetos, compreender sentenças simples, detectar hostilidade em uma voz, lembrar um evento, dentre tantas outras coisas, sem esperar ou optar por isso. Essas atividades não exigem intenção deliberada, esforço ou algum trabalho mental. Normalmente, o sujeito chega ao resultado sem atraso ou sinal de erro e nenhum sentimento noético precisa estar envolvido (PROUST, 2013). É o tipo de atitudes que Kahneman (2012) atribui às operações do Sistema 1 , nas quais a agência parece ausente ${ }^{19}$. Proust (2001) denomina essas ativi-

\footnotetext{
19 Segundo Kahneman (2012), os seres humanos possuem dois mecanismos distintos de processamento de informações, convencionalmente chamados de Sistema 1 (S1) e Sistema 2 (S2). O Sistema 1 é associado pensamento rápido, pois é imediato, automático e sem esforço, como, por exemplo, detectar que um objeto está mais perto que outro, compreender sentenças simples, ler palavras em grandes cartazes, fazer cara de aversão ao ver uma foto horrível etc.; e o Sistema 2 ao pensamento lento, pois exige um trabalho mental deliberado, laborioso e ordenado, como, por exemplo, procurar uma mulher de cabelos brancos, contar as ocorrências da letra a numa página de texto, preencher um formulário de imposto, verificar a validade de um argumento lógico complexo, entre outros.
} 
dades de operações mentais, isto é, "uma operação [que] transforma uma entrada em uma saída de acordo com um certo tipo de mecanismo em virtude de alguma regularidade funcional". Elas não têm nenhum objetivo em particular, não estão sob controle voluntário e, portanto, não podem ser obtidas deliberadamente.

Se parecemos realizar, na maior parte do tempo, operações mentais, o que suscita em nós a realização de ações mentais? A resposta de Proust (2013, p. 167) a esta pergunta é que "a estrutura motivacional dos atos mentais está associada a sinais de erro e a dúvidas autodirecionadas". Na vida ordinária, sinais de erro costumam acontecer quando os indivíduos praticam algum outro tipo de ação comum, como conversar, fazer compras, planejar uma viagem, arrumar malas, ou qualquer outra atividade cotidiana. Em outros contextos - como os acadêmicos e sociais -, filósofos, políticos, cientistas, físicos, dentre outros, também se deparam com sinais de erro e direcionam a si mesmos perguntas a fim de resolver problemas e tomar decisões. Isso significa que "uma ação cognitiva resulta da súbita percepção de que uma das condições prévias epistêmicas para uma ação em desenvolvimento não é atendida" (PROUST, 2013, p. 163).

O modo agente é solicitado quando há uma incompatibilidade epistêmica entre um estado mental desejado e um existente, fazendo com que o indivíduo revise seu plano de ação ou adquira o estado mental em questão, realizando um esforço cognitivo. Segundo Proust (2013, p. 163), “o agente não precisa representar essa situação de maneira substancialmente reflexiva. Ele só precisa se concentrar em como tornar sua ação possível”. E ele pode iniciar essa estratégia com uma pergunta autoendereçada, como, por exemplo, "posso lembrar os itens da lista de compras?".

No caso do comprador, quando ele chega ao supermercado, ele subitamente descobre que esqueceu a lista de compras e experimenta uma emoção desagradável que funciona como um sinal de erro, ou seja, uma précondição epistêmica para sua ação planejada não foi cumprida - ele não lembra os itens da lista. Assim que esse sinal de erro é produzido, a representação da sua ação muda para o modo de revisão, desencadeando uma ação mental que está relacionada tanto com o motivo instrumental - a ação mais abrangente - quanto com as normas epistêmicas relacionadas. Confor- 
me Proust (2013), neste exemplo, a sensibilidade à norma interfere nas diferentes ações que o agente pode tomar: 1) ele pode interromper as compras; 2) ele pode reconstituir a lista de itens usando a memória; e 3) ele pode comprar sem a lista, na expectativa de que andando pelo supermercado ele possa rastrear os itens necessários. Estas opções estão disponíveis para o agente apenas "se houver atos mentais no seu repertório e se ele puder selecionar uma opção com base em suas autoavaliações metacognitivas contextuais" (PROUST, 2013, p. 164).

Assim, podemos concluir que um sinal de erro ou uma dúvida autoendereçada causa uma motivação para a realização de uma ação mental. Este componente motivacional é dirigido para os fins instrumentais da ação abrangente - necessidade de informação -, enquanto o seu caráter epistêmico não envolve qualquer tipo de intenção do agente. Este último componente realizará a avaliação preditiva da ação mental e informará para o agente, por intermédio de sentimentos epistêmicos, se ele deve abortar a ação, se ele deve prosseguir com ela ou se ele deve adotar uma nova ação corporal, dado os recursos mentais disponíveis para ele naquele momento. Assim como realizará, também, uma avaliação retrospectiva da ação, informando ao agente, por meio de sentimentos epistêmicos, se ele alcançou o resultado esperado ou não, motivando o agente a considerar ações corretivas ou aceitar o desfecho.

A conclusão desta exposição é que, apesar do ato mental estar subordinado a uma ação mais abrangente que possui uma dada utilidade, a avaliação metacognitiva, que aplica as normas epistêmicas relacionadas à ação, é inteiramente realizada num nível inconsciente - controlada pelo ambiente dinâmico de maneira opaca, sem a participação controlada e consciente do agente. Este resultado leva à desconfiança na capacidade da agência epistêmica humana e põe em xeque o papel das normas epistêmicas.

Apesar desse desenlace, apresento, a seguir, um caso com algumas situações, que pretende apontar para a possibilidade de estabelecermos um papel para o agente cognitivo no domínio epistêmico, repercutindo nas considerações sobre a normatividade epistêmica.

\section{3. $O$ caso da terapeuta}


Como vimos na seção acima, as ações mentais estão normalmente incorporadas às ações ordinárias, uma vez que elas são motivadas por sinais de erro - durante o desempenho de uma tarefa - ou por dúvidas autodirecionadas - decorrentes da solução de um problema ou da tomada de decisões. Ações mentais são estimuladas na medida em que o agente necessita de informações sobre o seu ambiente, desse modo, elas fornecem os recursos cognitivos necessários para que eles possam atingir os seus objetivos, estando em perfeita continuidade com a agência não mental e com as ações corporais.

Assim, minha suposição é que mesmo que os indivíduos não possam controlar diretamente os processos de formação das suas crenças, sendo estas essencialmente receptivas, o agir no mundo requer que os indivíduos realizem alterações nas próprias propriedades mentais, que no contexto mais amplo das práticas humanas podem interferir: i) na seleção da estratégia e no comprometimento de se engajar numa tarefa cognitiva; e ii) no emprego correto dos resultados epistêmicos na resolução de questões práticas.

Em relação a (i), é sabido que um agente não pode controlar diretamente as suas ações mentais, no entanto, ele pode, dado o contexto e suas disposições, escolher a estratégia a ser empregada na tarefa e deliberadamente comprometer-se ou não em realizá-la, dirigindo a sua atenção concentrada para chegar a um resultado, como por exemplo: realizar um cálculo mental, verificar a validade de um argumento lógico complexo, selecionar fontes de informação confiáveis, buscar na memória um evento ou informação etc. Uma vez que normas instrumentais de utilidade e considerações de custo-benefício guiam a seleção de uma ação mental específica em um determinado contexto, é possível que o agente seja capaz de escolher a melhor estratégia de que dispõe e aplicá-la ou não, esboçando duas alternativas: a) essa escolha pode ser boa, se, de fato, o agente escolhe a melhor estratégia de que dispõe e se engaja neste processo; ou b) essa escolha pode ser ruim, se o agente é conscientemente negligente nesta escolha, não estando disposto a se engajar na atividade.

Já em relação a (ii), sabemos que o agente não tem controle sobre o conteúdo epistêmico das suas crenças, entretanto, ele pode deliberadamente decidir sobre suas afirmações públicas a respeito do resultado, com algumas 
alternativas: a) a afirmação sobre seu resultado epistêmico pode ser boa, se o agente é sincero e aplica corretamente o resultado que obteve; ou b) a ação sobre o resultado pode ser ruim, se o agente distorce a informação para interesse próprio ou outros interesses contrários à meta da ação mental.

Para corroborar essas intuições, apresento abaixo um caso hipotético - Caso da Terapeuta - que procura mostrar que o contexto das ações mentais epistêmicas é um contexto híbrido, que envolve a resolução de questões práticas/sociais usando recursos cognitivos. Isso exige um certo compromisso do indivíduo sobre sua ação no mundo, buscando não apenas alcançar metas epistêmicas, mas também a solução de problemas ordinários, demonstrando coerência e comprometimento com suas afirmações públicas.

\subsection{Mara, a terapeuta}

Mara é uma psicóloga clínica. Na sua atuação profissional, ela é movida pelo desejo de ser uma psicóloga de excelência - ajudando os seus pacientes a lidarem com seus problemas psicológicos com sucesso - e pela crença de que se comportando segundo as regras normativas da sua profissão e aplicando os melhores métodos e técnicas psicológicas na atuação com seus pacientes ela logrará esse êxito - para ajudar melhor seus pacientes, ela precisa buscar conhecimento confiável, a verdade é um meio para o fim prático. Mara, mesmo depois de formada, no intuito de melhorar a sua prática clínica, se debruça na leitura de livros e artigos sobre os últimos resultados de aplicação de técnicas psicoterápicas, participa de encontros e seminários com outros psicólogos clínicos, e está sempre discutindo seus casos com seus colegas.

Um dia, na sua prática clínica, ela utilizou um procedimento técnico que aprendeu para tratar um paciente, mas não obteve resultado. Utilizou-o com outros pacientes em novas ocasiões e, mais uma vez, não obteve sucesso. Ela chegou à crença de que "o procedimento $X$ não é adequado para o tratamento do distúrbio $\Psi "$ - crença $p$. Entretanto, conversando com um outro colega, tão experiente quanto ela, este lhe disse que tinha usado o mesmo procedimento diversas vezes e com muito sucesso, crendo em não $p$. 
Motivada pelo desejo de ser uma psicóloga de excelência, Mara começou a examinar criticamente a situação com o objetivo de chegar a uma crença verdadeira sobre o motivo pelo qual a sua aplicação da técnica está sendo um fracasso. Ela se deparou com um sinal de erro e, por isso, está colocando sob suspeita a sua crença de que "o procedimento $X$ não é adequado para o tratamento do distúrbio $\Psi$ ", ela não coloca apenas sob escrutínio a crença, mas também a base justificacional que ela tem para essa crença - a sua prática com o procedimento.

\section{- Situação 1}

Mara dispõe de algumas estratégias que pode utilizar para examinar criticamente a crença $p$ e comparar as visões alternativas:

- Ela pode usar a memória, para tentar lembrar os passos do protocolo da técnica;

- Ela pode buscar a opinião de outros colegas;

- Ela pode revisar o seu manual da técnica.

Esta escolha ocorrerá com base nas normas instrumentais de utilidade e considerações de custo-benefício, nas suas disposições adquiridas e no quanto ela está disposta em dispender tempo e esforço na tarefa.

Digamos que Mara empregue a ação mental de recuperação da memória direcionada para lembrar todos os passos da técnica. Ela realiza um esforço de atenção dirigida buscando ser precisa, a partir deste ponto, ela não tem nenhum controle sobre o resultado, pois as avaliações metacognitivas são realizadas em um nível subpessoal. O resultado da ação mental de Mara é um sentimento noético de incerteza. Ela se lembra claramente da técnica, mas algo lhe diz que não deve confiar na sua memória.

Alternativa 1.1: Com este sentimento de incerteza, Mara resolve mudar a estratégia e vai procurar o manual da técnica e dispende uma boa quantidade de tempo para ler e analisar atentamente todos os passos do protocolo, descobrindo que, realmente, ela estava pulando uma etapa da técnica e que, por isso, seus resultados tinham sido negativos, acreditando em $\sim p$. 
Alternativa 1.2: Mara ignora esse sentimento de incerteza, ela não está disposta a procurar o manual da técnica e realizar a leitura, então acaba mantendo a sua crença em $p$. Ela negligenciou o resultado da sua avaliação epistêmica, sendo irresponsável epistemicamente, o que implica que ela não estava comprometida com a meta da ação.

\section{- Situação 2}

Suponhamos que Mara escolheu a Alternativa 1.1. Ela escolheu as melhores estratégias que tinha disponível e chegou à crença de $\sim p$. Com este resultado, ela assumiu um compromisso para agir mentalmente ou para agir no mundo novamente.

- Alternativa 2.1: Com a mudança de crença, Mara agora volta a aplicar a técnica nos seus pacientes, seguindo o protocolo corretamente e tendo excelentes resultados, alcançando o seu objetivo de ser uma psicóloga de excelência.

- Alternativa 2.2: Com a mudança de crença, Mara não faz nenhuma alteração na sua prática clínica, pois ela é orgulhosa demais para assumir que estava errada e sente-se envergonhada frente ao colega. Ela omite a informação ou a distorce por interesse próprio. Ela não está sendo sincera e honesta com o resultado da sua avaliação cognitiva, indo de encontro à meta da ação mental.

\subsection{Discussão}

Este caso envolve uma situação ordinária e coloca a importância da noção de agência epistêmica para as práticas sociais cotidianas. Há um elemento agencial, neste caso, que influencia indiretamente a ação mental, e intervém nas afirmações sobre os resultados alcançados. A situação exposta acima envolve uma agente, no caso, uma psicóloga que é regida por um conselho de ética e é formada por uma instituição de ensino superior. É necessário que seja levado em consideração que ela saiba as regras de conduta do código de ética da sua profissão, assim como tenha estudado os princi- 
pais procedimentos da atuação clínica e as técnicas que aplica no seu exercício, tendo formado as disposições relevantes para a sua atuação profissional.

$\mathrm{A}(\mathrm{o})$ psicóloga(o) na sua formação é treinada(o) em práticas investigativas, ela(e) é orientada(o) a procurar ajuda caso tenha dificuldades, aprende a aplicar as melhores regras normativas em situações do exercício clínico, assim como a realizar análises sobre diversos assuntos dentro de um contexto psicológico. Tudo isso considerado, significa que Mara deve ter no seu repertório as disposições básicas para resolver questões relacionadas à sua área de atuação. Se ela assim não o faz, pode ser responsabilizada pela sua conduta, porque, neste contexto, a sua ação não é apenas direcionada para um fim epistêmico - a verdade sobre $p-$, mas também para sua meta prática - ser uma psicóloga de excelência.

Ao analisar este caso como um exemplo de agência epistêmica alguns pontos devem ser levados em consideração: i) encontrar-se em uma situação de conflito cognitivo, decorrente de algum sinal de erro, e possuir a disposição para considerar o contexto da ação mental são condições necessárias para a agência epistêmica. Quando um indivíduo está numa situação de conflito cognitivo, isto é, quando ele percebe que uma das condições prévias epistêmicas não é atendida no desenvolvimento de uma ação, faltando alguma informação básica para a resolução de um problema, ele, possuindo a disposição adequada, é movido pelo motivo instrumental de encontrar uma resposta, o que resultará no direcionamento da sua atenção para a tarefa, ativando as operações metacognitivas que lhe fornecerão um resultado epistêmico. Assim, encontrando-se numa situação de conflito cognitivo, Mara deve ser capaz de deliberadamente considerar o contexto no qual está inserida para selecionar a melhor estratégia ${ }^{20}$ a ser seguida naquela situação, ou até mesmo abster-se de realizar a ação mental naquele momento, por ter consciência de que outros fatores podem atrapalhar o foco da sua atenção, por exemplo.

Outra condição necessária para a agência epistêmica é que ii) o indivíduo tenha a intenção de se engajar adequadamente em relação à meta da

\footnotetext{
${ }^{20}$ Aqui deve ser considerado as capacidades e limitações do agente, o elemento humano não pode ser desconsiderado nesta hipótese. Não deve ser exigido que Mara empregue a regra normativa mais correta na situação, mas sim a melhor regra que ela possui no seu repertório de disposições.
} 
sua ação mental. Se a estratégia escolhida foi a precisão da memória direcionada, Mara deve buscar precisamente todos os passos envolvidos no protocolo, dispendendo tempo e esforço cognitivo para executar a tarefa a fim de ser sensível aos requisitos normativos da meta. Caso ela se disperse facilmente, e não consiga exercer um autocontrole sobre a tarefa dirigida, é possível que ela seja guiada por uma norma de fluência, ao invés de uma norma de precisão e, assim, cometa erros.

De acordo com Kahneman (2012, p. 38-39), o melhor que podemos fazer para evitar erros significativos quando há muita coisa em jogo, é aprender a reconhecer situações em que os enganos são prováveis e se esforçar para evitá-los, "por meio do monitoramento acentuado e da atividade diligente do Sistema 2" que exige atenção e, normalmente, é interrompido quando a atenção é desviada. Assim, se Mara consegue direcionar a sua atenção adequadamente, ela terá maior probabilidade de evitar o uso de heurísticas e vieses na sua tarefa - desvios cognitivos que distorcem o pensamento para fazê-lo se encaixar em conceitos preconcebidos, que moldam a maneira de interpretar uma informação - quando estiver avaliando questões psicológicas que estão dentro dos limites das suas disposições.

Enquanto uma agente epistêmica, Mara pode ser responsável por algumas falhas, mas não por outras. Mara pode falhar em considerar adequadamente o contexto no qual está inserida, selecionando uma estratégia inadequada para ser seguida naquela situação - por estar com preguiça, por exemplo -, ou até mesmo insistir em prosseguir com a ação mental quando as condições não forem satisfatórias - quando ela estiver com dor de cabeça, por exemplo, atrapalhando o foco da sua atenção. Nestes casos, as suas falhas poderiam ter sido evitadas caso ela tivesse sido mais cuidadosa, sendo, portanto, responsável por elas. Entretanto, "não está claro se um agente metacognitivo deve ser responsabilizado por suas avaliações" (PROUST, 2013, p. 206), ou seja, pelo conteúdo epistêmico dos seus resultados, pois embora ele seja sensível aos requisitos normativos associados às estratégias que ele mesmo escolheu, ele não tem controle voluntário sobre esses processos metacognitivos, dependendo dos seus sentimentos epistêmicos para analisar a viabilidade de suas ações mentais. 
Destarte, ser um agente epistêmico depende de estar adequadamente motivado para um fim epistêmico-motivacional e possuir as disposições relevantes para alcançar esse fim, que serão eliciadas quando o indivíduo se encontrar em uma situação de conflito cognitivo. Isso não significa dizer que o agente epistêmico está no controle do processo de revisão e formação de crenças ou que o resultado epistêmico dependa das suas intenções ou das suas habilidades reflexivas. O agente, neste processo, tem (1) o papel de deliberadamente se comprometer com a tarefa, influenciando indiretamente a ação mental; ele pode escolher uma estratégia que não condiz com o contexto em que se encontra ou decidir não se engajar adequadamente na tarefa. $\mathrm{O}$ agente epistêmico também (2) é responsável pelas suas afirmações acerca do conteúdo epistêmico das suas crenças, aplicando corretamente a informação ou distorcendo-a por interesse próprio, não havendo o alinhamento da afirmação pública com suas crenças privadas. Tanto (1) quanto (2) repercutem no desfecho da ação mental, interferindo indiretamente no resultado epistêmico e diretamente no núcleo da ação global, que busca resolver o problema ordinário.

A grosso modo, esta concepção de Agência Epistêmica Híbrida pode ser apresentada da seguinte forma:

[AgE-H] Ação mental direcionada para um fim epistêmicomotivacional que atua diretamente na escolha da estratégia, no engajamento e comprometimento do agente em resolver uma questão ou tomar decisões, assim como no emprego correto dos resultados epistêmicos; e atua indiretamente no resultado epistêmico da tarefa.

Em uma ação mental, as normas epistêmicas que dirigem a ação atuam de modo subpessoal, impedindo o indivíduo de, deliberadamente, escolher o resultado cognitivo. Entretanto, a ação mental possui um aspecto híbrido, já que é subordinada a uma ação mais abrangente que é motivada instrumentalmente, tendo o agente, portanto, um papel ativo na sua condução. Este duplo aspecto, ou "estrutura de duas camadas" das ações mentais utilizando a denominação de Proust (2013) - permite que o agente seja responsável tanto pela escolha da estratégia epistêmica, quanto pela quantidade de esforço empregada na sua realização. Embora estes fatores não atuem diretamente no resultado epistêmico, eles são de primordial importância para a 
condução de todo o processo, pois, sem a aplicação da estratégia adequada e sem o esforço cognitivo da atenção, é improvável que o agente ative adequadamente os seus processos metacognitivos para chegar a um resultado, podendo, assim, ser considerado irresponsável epistemicamente.

Os resultados das avalições epistêmicas do agente dependem da qualidade dos feedbacks que ele recebeu ao longo da vida, sendo moldados pelo seu ambiente dinâmico e pelas suas experiências, portanto, como aponta Proust (2013), só resta ao agente confiar nos seus sentimentos epistêmicos e nas suas experiências passadas. Mas quando o agente distorce o seu resultado, manipulando-o para se adequar a outros interesses que não o interesse inicial da ação mental - obter uma informação para solucionar um problema, por exemplo - ele está indo de encontro à meta da ação mental como um todo, sendo inconsistente com a sua ação, podendo ser, então, acusado de irresponsabilidade epistêmica.

\subsection{Considerações sobre o papel do agente e a normatividade}

A concepção de Agência Epistêmica Híbrida (AgE-H) defendida neste trabalho contraria a noção de Agência Epistêmica Reflexiva (AgE-R) em alguns pontos fundamentais: i) Enquanto para Sosa o agente possui um controle direto sobre o resultado epistêmico da sua ação mental, na concepção híbrida o agente possui apenas um controle indireto, de modo que ele não pode decidir livremente no que crer. O que está sob seu controle é o grau de engajamento e esforço na realização da atividade, a escolha da estratégia - dentro do contexto das suas disposições adquiridas - e o emprego dos resultados obtidos. ii) No conceito de Sosa, o agente é capaz de reconhecer a confiabilidade do processo de formação de suas crenças e defender a sua perspectiva epistêmica de forma confiável, já esta nova formulação considera que o processo de formação de crença é, em parte, opaco ao agente, pois envolve muitos processos subpessoais, o que inviabiliza o acesso imediato e transparente do agente aos seus processos cognitivos, incapacitando-o de possuir uma ampla perspectiva epistêmica sobre a fonte das suas crenças. 
Esta conclusão aponta para algumas considerações que merecem ser discutidas: i) a adoção de uma visão mais realista sobre o papel do agente cognitivo no domínio epistêmico; e, consequentemente, ii) os limites da normatividade epistêmica dentro de uma visão naturalizada das ações mentais.

Os estudos na área da Psicologia Cognitiva têm influenciado cada vez mais os debates em torno dos problemas epistemológicos, principalmente, por meio da vertente filosófica naturalista, que acredita que os empreendimentos filosóficos devem estar conectados às ciências ${ }^{21}$. Uma série de filósofos defendem uma metodologia naturalista para a resolução de problemas epistemológicos (STICH; NISBETT, 1980; GOLDMAN, 1991; KITCHER, 1992; HAACK, 1993; KORNBLITH, 1994; PROUST, 2013). Eles afirmam que os resultados empíricos sobre a cognição humana podem ser muito úteis, senão essenciais, para o desenvolvimento da epistemologia, ou seja, que o estudo das limitações e capacidades biológicas e psicológicas humanas não podem ser desconsiderados quando o objeto de estudo é o conhecimento humano.

De acordo com Feldman (2012), há três razões principais apontadas pelos naturalistas para a defesa de que os resultados psicológicos exercem um papel importante no desenvolvimento e na análise dos conceitos epistêmicos: i) "a análise adequada utiliza conceitos da psicologia" (p. 275), isto é, quando se analisa conceitos como conhecimento e justificação, inevitavelmente, conceitos da psicologia serão evocados para a sua compreensão, como crença e evidência, por exemplo; ii) "resultados empíricos podem resultar em modificações de análises” (p. 278), uma vez que uma evidência científica pode levar os epistemólogos a revisar ou abandonar determinados conceitos; e iii) "a análise científica é mais útil que a análise conceitual” (p. 283 ), isso porque métodos puramente especulativos introduzem erros nas análises sobre o conhecimento, e tais erros podem ser evitados por um estudo empírico.

Assim, é possível que os resultados deste trabalho sobre o papel do agente cognitivo no domínico epistêmico, com base em resultados empíri-

\footnotetext{
${ }^{21}$ Não há um consenso entre os filósofos naturalistas sobre o grau de influência que os resultados científicos devem ter sobre os projetos epistemológicos. Para uma compreensão mais aprofundada sobre as diferentes posições filosóficas naturalistas, ver James Maffie (1990).
} 
cos das Ciências Cognitivas, nos levem a uma melhor explicação sobre o desenvolvimento das ações mentais e, consequentemente, a uma modificação sobre a forma como nos vemos como agentes epistêmicos. Ao invés de adotarmos uma visão superestimada sobre os nossos poderes e capacidades metacognitivos - como propõe o projeto epistemológico de Sosa -, podemos aderir a uma visão mais realista sobre o nosso funcionamento cognitivo, tornando-nos mais conscientes sobre aquilo que somos capazes de realizar no domínio epistêmico para dirigirmos nossos esforços nesta direção.

As consequências de uma percepção mais fidedigna, baseada na Psicologia Cognitiva, sobre nós mesmos enquanto agentes cognitivos, repercutem no campo da normatividade epistêmica. Como uma disciplina tradicionalmente voltada para a avaliação de bens epistêmicos, por meio de normas e deveres intelectuais - deontologismo epistêmico - ou pela performance cognitiva de um agente - epistemologia das virtudes -, a noção de normatividade epistêmica também é passível de sofrer modificações em suas análises quando se adota uma visão naturalizada das ações mentais como proposto neste trabalho -, pois modificam-se as fontes sobre as quais se baseia a sua força normativa.

O modelo de agência epistêmica proposto neste trabalho tem como base a afirmação que a ação mental é constituída por dois aspectos, um instrumental e outro epistêmico, tendo, portanto, um caráter híbrido. $\mathrm{O}$ aspecto instrumental se refere ao desejo do agente de resolver uma questão ou tomar uma decisão, já o aspecto epistêmico diz respeito à meta epistêmica inerente à resolução da tarefa - sem a qual não seria possível completá-la -, de modo que os dois aspectos precisam atuar conjuntamente para que a tentativa seja considerada uma ação mental. É necessário que o agente, ao realizar a ação mental, esteja realmente focado em empreender a ação, e isso só será possível se ele empregar objetivos epistêmicos, visto que, como afirma Proust (2013, p. 152), as ações mentais "herdam os requisitos normativos que já se aplicam às suas pré-condições e resultados epistêmicos". Caso o agente empreenda a ação mental sem empregar os requisitos normativos, essa tentativa será apenas uma tentativa ilusória. 
No nível epistêmico, não há nenhuma possibilidade de intervenção consciente e direta do agente, já no nível instrumental, é necessário que o agente realize adequadamente os cálculos de custo-benefício e dirija adequadamente a sua atenção para que o propósito da ação seja realizado. Assim, é possível afirmar que, neste modelo, a força normativa seja proveniente da utilidade de seguir a norma, sendo, portanto, pragmática.

Uma concepção pragmática da normatividade epistêmica compreende as normas epistêmicas como uma subespécie das normas da racionalidade prática. Segundo Motiva (2011), os pragmatistas em relação à normatividade se dividem em radicais e moderados. Os primeiros "concebem as normas epistêmicas como quaisquer procedimentos epistêmicos que promovam de maneira ótima nossas metas, e negam que os procedimentos conducentes à verdade se encontrem entre estes procedimentos [...]" (p 330, grifo da autora). Já os segundos, "pensam que seguir procedimentos conducentes à verdade é a melhor maneira de formar nossas crenças desde o ponto de vista do êxito de nossas metas" (p. 330).

Acredito que o modelo defendido aqui vai ao encontro de uma perspectiva pragmatista moderada sobre as normas epistêmicas, tal qual a defendida por Hillary Kornblith no seu artigo de 1993, "Epistemic Normativity". Neste artigo, Kornblith (1993) afirma que a avaliação epistêmica tem um papel especial, justamente porque temos o interesse que nosso sistema cognitivo realize avalições relativas aos nossos múltiplos objetivos e que chegue a esses resultados com precisão. Assim, quando seguimos normas epistêmicas, temos uma maior probabilidade de alcançar os objetivos instrumentais da ação mental, algo que não alcançaríamos caso deixemos que considerações pragmáticas afetem o processo de formação de crença. Para Kornblith (1993, p. 373),

[...] a avaliação epistêmica encontra seu fundamento natural em nossos desejos, de tal maneira que faz da verdade algo que devemos nos importar, independentemente de valorarmos outras coisas. Isto nos proporciona uma explicação pragmática da fonte da normatividade epistêmica, mas uma explicação que é universal e que também permite que a verdade desempenhe um papel central. Os pragmatistas costumam sugerir que a avaliação epistêmica tem pouco a ver com a verdade; mas, se estou certo, é por razões pragmáticas que a verdade tem a importância que tem na avaliação epistêmica. 
Desse modo, a agência epistêmica está sujeita às avaliações epistêmicas desde uma perspectiva pragmática destas normas. Entretanto, diferente de Kornblith (1993), assumo com Proust (2013) que algumas ações mentais tenham, além da verdade, outras normas epistêmicas (coerência, relevância etc., não se restringindo apenas à verdade), que podem ser empregadas de acordo com o contexto relevante. De acordo com Proust (2013, p. 305-307),

[...] as normas epistêmicas têm um caráter objetivo e constitutivo, fundamentado nas formas admissíveis de gerenciar informações, que não dependem de preferências individuais ou necessidades contextuais. [...] As pessoas podem variar, culturalmente, nos tipos de ação mental que são motivadas a executar em um determinado contexto. Mas isso não significa que eles tenham critérios diferentes para o que conta como computação precisa, memória exaustiva ou posição consensual em uma determinada tarefa cognitiva bem identificada.

Assim, o que deve ser avaliado numa ação mental é o engajamento do sujeito na realização da ação, representado pelo seu fim epistêmico-motivacional. As avaliações metacognitivas que ocorrem em decorrência dessas ações não podem ser objetos de avaliações epistêmicas - embora também empreguem normas epistêmicas -, uma vez que são realizadas por processos subpessoais que independem da intenção do agente, e que são determinadas por outros fatores, como o contexto dinâmico em que o agente está inserido.

Outra ação que é passível de avaliação epistêmica e, portanto, sujeita a regras normativas, são as afirmações que o agente faz acerca do seu resultado epistêmico. Segundo Bernard Williams (1973), as crenças apresentam uma característica que explica a nossa incapacidade psicológica de crer de acordo com a nossa vontade, que é a sua propriedade de apontar a verdade. O fato de que a verdade seja uma dimensão primária de avaliação de uma crença impede que um sujeito possa acreditar por qualquer outra razão que não esteja relacionada com a verdade, se ele assim o faz, significa que não tem uma boa razão para acreditar na proposição, e isso equivale a pô-la em dúvida.

Embora não possamos formar crenças de acordo com a nossa vontade, isto é, não sejamos capazes de decidir no que crer, para Williams (1973) é possível fazer uma relação entre crença e decisão. Esta conexão pode ser 
estabelecida "entre a crença genuína e a decisão de dizer ou não dizer o que creio, a decisão de usar palavras para expressar, ou não, o que creio. Esta decisão tem a ver, entretanto, com o que dizemos e fazemos [...]" (WILLIAMS, 1973, p. 147). Além de poder decidir expressar ou não a minha crença, também está sob o meu controle afirmar a minha crença com sinceridade ou não, como aponta Williams (1973, p. 140): “[...] é possível que alguém afirme que $p$ e trate de conseguir que outros pensem que $p$, e creiam que ele crê que $p$, ainda que de fato não seja assim”. Desse modo, mesmo que os agentes não tenham controle sobre seus resultados epistêmicos, eles podem sofrer avaliações quanto às suas omissões e quanto à veracidade ou não das suas afirmações acerca dos seus estados epistêmicos.

A proposta de agência epistêmica apresentada neste trabalho pretende atender às intuições naturalistas sobre o funcionamento cognitivo humano, sem deixar de lado o apelo normativo que sempre fez parte da tradição epistemológica, que tem a ver com a complexa relação entre o sujeito cognitivo e o mundo. Embora esta proposta não se coadune com abordagens que afirmam a liberdade epistêmica dos agentes em relação às suas crenças como a Epistemologia das Virtudes apresentada por Sosa -, ela assume a posição de que, ainda assim, o agente possui um papel importante no domínio epistêmico, mesmo que sujeito a limitações restritivas provenientes da configuração biológica do seu aparato cognitivo.

\section{Conclusão}

O objetivo deste trabalho foi propor um modelo de agência epistêmica que atendesse ao projeto normativo da epistemologia, satisfazendo as intuições naturalistas sobre o funcionamento cognitivo humano. Assim, apoiada nas afirmações de Proust sobre a camada dupla da estrutura das ações mentais, que acomoda tanto requisitos instrumentais quanto requisitos normativos, apresentei um caso hipotético para mostrar a possibilidade da agência epistêmica.

Com o caso da terapeuta, tive a intenção de mostrar que mesmo que os indivíduos não possam controlar diretamente os processos de formação das suas crenças, sendo estas essencialmente receptivas, as ações mentais 
epistêmicas são realizadas em um contexto híbrido que envolve a resolução de questões práticas/sociais usando recursos cognitivos, de modo que i) o engajamento e a seleção das estratégias de aquisição de crenças, assim como ii) o emprego correto dos resultados epistêmicos na resolução de questões práticas, repercutem no desfecho da ação mental, interferindo indiretamente no resultado epistêmico e diretamente no núcleo da ação global, que busca resolver o problema ordinário. Isso significa que há um papel para a agência no domínio epistêmico, uma vez que os processos metacognitivos dependem do engajamento do agente na tarefa, como também a meta da ação mental depende, em parte, da escolha do agente em afirmar verdadeiramente ou não o seu resultado epistêmico.

Este resultado sobre o papel do agente cognitivo no âmbito epistêmico contraria o conceito de agência epistêmica concebido por Sosa e leva à adoção de uma visão mais realista sobre o funcionamento cognitivo humano, contribuindo para a tomada de consciência sobre suas capacidades e limitações, ademais de auxiliar em relação à direção que devem empreender os seus esforços. A adesão a esta perspectiva também repercute na compreensão sobre a normatividade epistêmica, que não segue um modelo baseado em deveres epistêmicos ou virtudes intelectuais, mas adota uma concepção pragmática moderada, que avalia as ações epistêmicas a partir do seu fim epistêmico-motivacional.

Por limitações do próprio escopo deste trabalho, não foi possível avaliar os impactos desta proposta em outros temas que são importantes para a epistemologia, como: a definição de conhecimento, o problema do valor do conhecimento, a demarcação dos objetivos epistêmicos, a noção de virtudes intelectuais, entre outros. Acredito que futuras investigações sobre a análise deste modelo de agência epistêmica e sua relação com outros problemas epistemológicos possam enriquecer esta proposta, tornando-a uma perspectiva promissora em fomentar debates no campo da epistemologia.

\section{Referências}

ALSTON, W. Internalism and externalism in epistemology. Philosophical Topics, v. 14, n. 1, Papers on Epistemology ,p. 179-221, 1986. 
Internalism and externalism in epistemology. In CRAIG, E. (Ed.). Routledge Encyclopedia of Philosophy. London and New York: Routledge, 1998, p. 4014-4018.

. Beyond "justification": dimensions of epistemic evaluation. London: Cornell University Press. 2005.

BERMÚDEZ, J. L. Thinking Without Words. New York: Oxford University Press, 2003.

BONJOUR, L.; SOSA, E. Epistemic justification: internalism vs. externalism, foundations vs. virtues. United Kingdom: Blackwell Publishing, 2003.

BURTON, R. Sobre ter certeza: como a neurociência explica a convicção. São Paulo: Blucher, 2017.

CHISHOLM, R. The Indispensability Of Internal Justification. Synthese, v. 74, p. 285-296, 1988.

. Theory of Knowledge. Englewood Cliffs: Prentice-Hall, 1989.

CODE, L. Epistemic Responsibility. Hanover, NH: University Press of New England, 1987.

CUSSINS, A. The connectionist construction of concepts. In BODEN, M. (Ed.) The Philosophy of Artificial Intelligence. Oxford: Oxford University Press, 1990, p. 380-400.

DAMASIO, A.; EVERITT, B.; BISHOP, D. The somatic marker hypothesis and the possible functions of the prefrontal cortex [and discussion]. Philosophical Transactions: Biological Sciences, v. 351, n. 1346, p. $1413-$ 1420, 1996.

DAVIDSON, D. Actions, Reasons, and Causes. In: Essays on Actions and Events. 2a Ed. Oxford: Oxford Clarendon Press, 2001a. p. 3-19. Publicado originalmente em 1963.

Agency. In: . Essays on Actions and Events. $2^{\mathrm{a}}$ Ed. Oxford: Oxford Clarendon Press, 2001b, p. 43-61. Publicado originalmente em 1971.

DEPAUL, M. Value monism in epistemology. In STEUP, M. (Ed.). Knowledge, Truth, and Duty: Essays on Epistemic Justification, Responsibility, and Virtue, Oxford: Oxford University Press, 2001, p. 170185.

ENGEL, P. On the very idea of epistemic agency. In: EGIDI, R.; DE CARO, M. (Eds.). The architecture of knowledge. Corocci: Rome, 2010. 
FAIRWEATHER, A. Bridges Between Virtue Epistemology and Philosophy of Science. In: . (Ed.). Virtue Epistemology Naturalized: bridges between virtue epistemology and philosophy of science. New York: Springer, 2014. p. 1-9.

FELDMAN, R. Naturalismo metodológico na epistemologia. In GRECO, J.; SOSA, E. (Org.). Compêndio de Epistemologia. São Paulo: Edições Loyola, 2012, p. 271-296.

GOLDMAN, A. Epistemic Folkways and Scientific Epistemology. In . Liaisons: Philosophy Meets the Cognitive and Social Sciences. Cambridge: The MIT Press, 1991, p. 155-175.

GRECO, J. Agent Reliabilism, Philosophical Perspectives, v.13, p. 273 296, 1999.

HAACK, S. Evidence and inquiry. Oxford: Blackwell, 1993.

KAHNEMAN, D. Rápido e devagar: duas formas de pensar. Rio de Janeiro: Objetiva, 2012.

KITCHER, P. The naturalists return. The Philosophical Review, n. 101, p. 53-114, 1992.

KORNBLITH, H. Epistemic Normativity, Synthese, v. 94, n. 3, p. 357-376, 1993.

. Introduction: what is naturalized epistemology? In

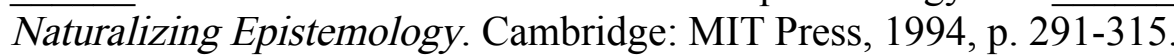

(Ed.).

. Epistemology: internalism and externalism. Oxford: Blackwell Publishers, 2001.

. Sosa on human and animal knowledge. In: GRECO, J. (Ed.). Ernest

Sosa and his critics. Oxford: Blackwell, 2004. p. 126-134.

. Knowledge needs no justification. In: SMITH, Q. (Ed.). Epistemology: New Essays. Oxford: Oxford University Press, 2008. p. 5-23. 2009

. Sosa in perspective. Philosophical Studies, n. 144, p. 127-136,

. What Reflective Endorsement Cannot Do. Philosophy and Phenomenological Research, v. LXXX, n. 01, January, p. 1-19, 2010.

. On reflection. Oxford: University Press, 2012.

. How central are judgment and agency to epistemology?. Philos Stud, v. 174, n. 10, p. 2585-2597, 2016 a. 
. Epistemic Agency. In: VARGAS, M. A. F. (Ed.). Performance Epistemology: Foundations and Applications. Oxford: Oxford University Press, 2016b. p. 167-181.

KVANVIG, J. Truth is not the primary epistemic goal. In STEUPS, M.; SOSA, E. (Eds.) Contemporary Debates in Epistemology, Oxford: Blackwell, 2005, p. 285-296.

MAFFIE, J. Recent work on naturalized epistemology. American Philosophical Quartely, n. 27, p. 281-293, 1990.

MCDOWELL, J. The content of perceptual experience, The Philosophical Quarterly, v. 44, n. 175, p. 190-205, 1994.

MONTMARQUET, J. Epistemic Virtue and Doxastic Responsibility. Lanham: Rowman and Littlefield, 1993.

MOTIVA, V. La Normatividad de la creencia: Introducción. In: VALDÉS, M.; FERNÁNDEZ, M. (Eds.). Normas, virtudes y valores epistémicos: ensayos de epistemologia contemporânea. México: UNAM, Instituto de Investigaciones Filosóficas, 2011. p. 325-336.

NISBETT, R.; WILSON, T. Telling More Than We Can Know: Verbal Reports on Mental Processes. Psychological Review, n. 84, p. 231-259, 1977.

PEACOCKE, C. Does perception have a nonconceptual content? The Journal of Philosophy, v. 98, n. 5, p. 239-64, 2001.

PROUST, J. A plea for mental acts. Synthese, v. 129, p. 105-128, 2001.

. Epistemic Agency And Metacognition: An Externalist View. Proceedings of the Aristotelian Society, v. 108, p. 241-268, 2008.

. Metacognition. Philosophy Compass, v. 11, n. 5, p. 989-998, 2010.

. The Philosophy of Metacognition: mental agency and selfawareness. Oxford: Oxford University Press, 2013.

QUINE, W. V. A Relatividade Ontológica. In: RYLE, G., AUSTIN, J. L., QUINE, W. V., STRAWSON, P. F. Ensaios. São Paulo: Abril, 1980, p. 133156. (Col. Os Pensadores).

SCHLOSSER, M. Agency, In Zalta, E. (Ed.). The Stanford Encyclopedia of Philosophy, 2015. Disponível em:

$<$ https://plato.stanford.edu/archives/fall2015/entries/agency/ $>$. Acesso em 13 mai 2018. 
SCHWARZ, N.; CLORE, G. Feelings and phenomenal experiences. In HIGGINS, E.; KRUGLANSKI, A. (Eds.). Social Psychology: Handbook of Basic Principles. New York: Guilford Press, 1996, p. 385-407

SMITH, J. Studies of uncertainty monitoring and metacognition in animals and humans. In TERRACE, H. S.; METCALFE, J. (Eds.). The Missing Link in Cognition: Origins of Self-reflective Consciousness. New York: Oxford University Press, 2005, p. 242-271.

SMITH, J.; SHIELDS, W.; WASHBURN, D. The comparative psychology of uncertainty monitoring and metacognition. Behavioral and Brain Sciences, v. 26, Ed. 3, pp. 317-339, 2003.

SOSA, E. The Raft and the Pyramid: coherence versus foundations in the theory of knowledge, Midwest Studies in Philosophy, n. 5, p. 3-25, 1980.

Press, 1991.

Knowledge in Perspective. Cambridge: Cambridge University

. Beyond Internal Foundations to External Virtues. In: BONJOUR,

L.; SOSA, E. Epistemic Justification: Internalism vs. Externalism; Foundations vs. Virtues. Oxford: Blackwell, 2003. p. 99-170.

. A Virtue Epistemology: apt belief and reflective knowledge, Vol I. Oxford: Oxford University Press, 2007.

. Reflective Knowledge: apt belief and reflective knowledge, Vol. II.

Oxford: Oxford Unidersity Press, 2009.

. Knowing Full Well. Princeton: Princeton University Press, 2011.

Judgment and Agency. Oxford : Oxford University Press, 2015.

STICH, S.; NISBETT, R. Justification and the psychology of human reasoning. Philosophy of Science, n. 47, p. 188-202, 1980.

VELLEMAN, D. What Happens When Someone Acts? Mind, v. 101, n.403, p. 461-481, 1992.

WILLIAMS, Bernard. Deciding to believe. In Problems of the Self: Philosophical Papers (1956-1972). New York: Cambridge University Press, 1973, p. 136-151.

ZAGZEBISK, L. Virtues of the Mind. Cambridge: Cambridge University Press, 1996. 